BIOMEDICA

Vol. 3, No. 3 - 1983

\title{
REVISIONES
}

\section{LEISHMANIAS IS}

\section{GERZAIN RODRIGUEZ TORO. *}

\section{DEFINICION}

Las leishmaniasis son zoonosis què afectan la piel, las mucosas o las vísceras, resultantes del parasitismo de los macrófagos por un protozoario flagelado del género Leishmania, introducido al organismo por la picadura de un insecto flebotomíneo.

\section{MORFOLOGIA}

El género Leishmania (L) comprende formas amastigotes y promastigotes. Las primeras se presentan en los macrófagos del huésped vertebrado, miden 2-3 micras de diámetro, son ovoides y constan de un núcleo excéntrico y de un citoplasma claro (Figs. 1-3), en el que resalta una estructura elongada muy basófila, el kinetoplasto (Figs. 2-3). Por microscopía electrónica se reconocen numerosos microtúbulos por dentro de la membrana celular, que sirven de citoesqueleto (Fig. 3); el kinetoplasto se ve como una mitocondria que se extiende circularmente por la mayoría del protozoario y que en la vecindad del flagelo presenta unos filamentos entrelazados y compactos que corresponden a $A D N$ (Fig. 3). En su vecindad se origina el flagelo que está alojado en una hendidura flagelar; tiene la característica imagen de 9 pares de túbulos periféricos y un par central. En el citoplasma hay ribosomas libres y un aparato de Golgi junto con gránulos densos y claros, variables según las especies (Figs. 2-3). Los amastigotes se dividen por fisión binaria y pueden verse libres, cuando el macrófago se desintegra.
Las formas promastigotes se encuentran en el insecto vector y en el cultivo. Son elongadas, miden 15-40 x 3 micras, tienen un núcleo central y un kinetoplasto desplazado hacia el extremo anterior, del cual emerge un largo flagelo (Fig. 4-5). El citoplasma tiene gran número de microtúbulos submembranosos y una variedad de gránulos de densidad variable, ribosomas, acúmulos de vesículas paraflagelares o vecinas al aparato de Golgi, que es muy prominente, y consta de lamelas, vacuolas y vesículas (Figs. 4-7).

\section{VECTORES}

Los insectos que transmiten la leishmaniasis son dípteros diminutos (2-3) mm, conocidos en nuestro medio por múltiples nombres regionales, el más frecuente de los cuales es "capotillo" (1). Pertenecen a la sub-familia Phlebotominae y al género Lutzomyia (Lu) del cual han sido identificadas en Colombia alrededor de 110 especies, pero solo unas pocas de ellas son eficientes vectores de la enfermedad (1). Lu. trapidoi se ha encontrado naturalmente infectada en Colombia (1). Los insectos tienen hábitos selváticos, rurales o suburbanos y diferentes grados de afinidad por diversos huéspedes (2) lo cual origina características epidemiológicas definidas a la enfermedad. Sólo la hembra es antroprofílica y hematófaga. Los promastigotes se multiplican en el tubo digestivo del insecto en el cual ocupan zonas definidas, según el grupo de leishmaniasis (3). Las cepas de L. braziliensis se desarrollan en los tres segmentos del tubo digestivo

\footnotetext{
* Patólogo, Grupo de Patología, Instituto Nacional de Salud, A.A. 80334, Bogotá. Profesor Asociado de Morfología, Facultad de Medicina, Universidad Nacional. Dermatopatólogo, Hospital Militar, Bogotá.
} 


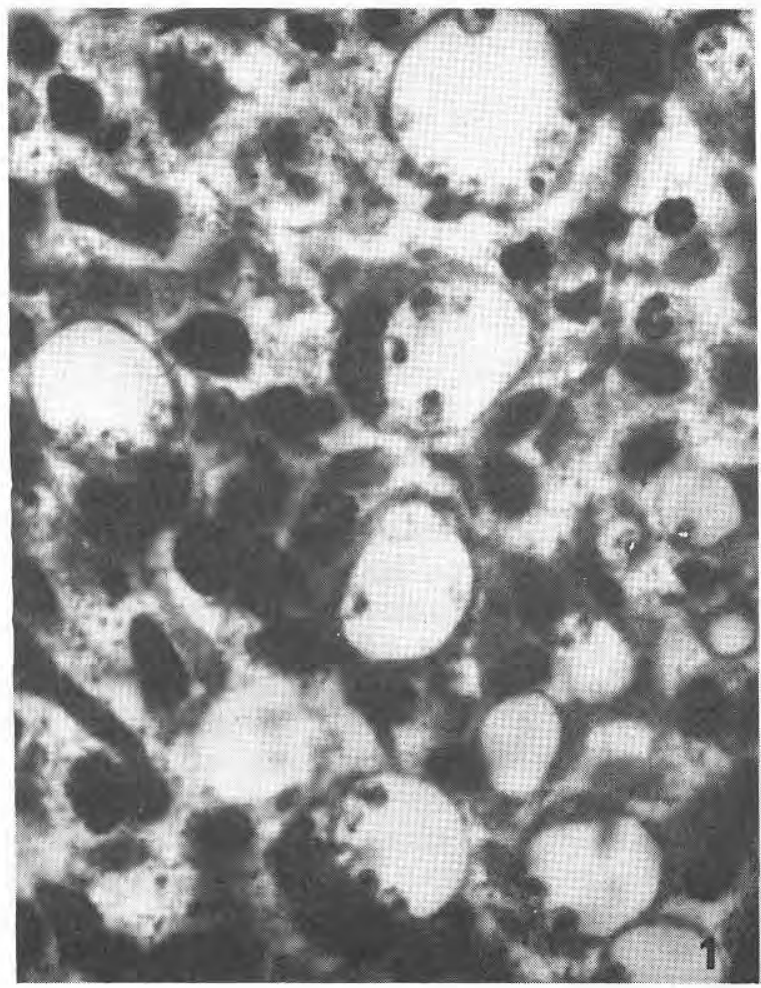

Fig. 1. M acrófagos vacuolados con numerosas leishmanias en el fagolisosoma. Corte de 1 micra incluído en resinas y teñido con Azul de Toluidina 1.000 X. Leishmaniasis difusa.

(anterior, medio y posterior); las cepas de $L$. mexicanase desarrollan en los dos primeros $(2,3)$.

\section{RESERVORIOS}

La leishmaniasis es una enfermedad primaria de pequeños mamíferos, principalmente roedores, desdentados y marsupiales (L. cutánea y mucocutánea) $(2,4-6)$ y de cánidos (L. visceral) $(2,4,7)$. Los pequeños roedores de monte son la fuente principal de infección en algunas áreas $(2,4,6)$. En Panamá, el perezoso (Choloepus hoffmanni) es un reservorio importante (5).

En Colombia no se han demostrado todavía reservorios infectados naturalmente con cepas de la L. cutánea o cutáneo-mucosa,

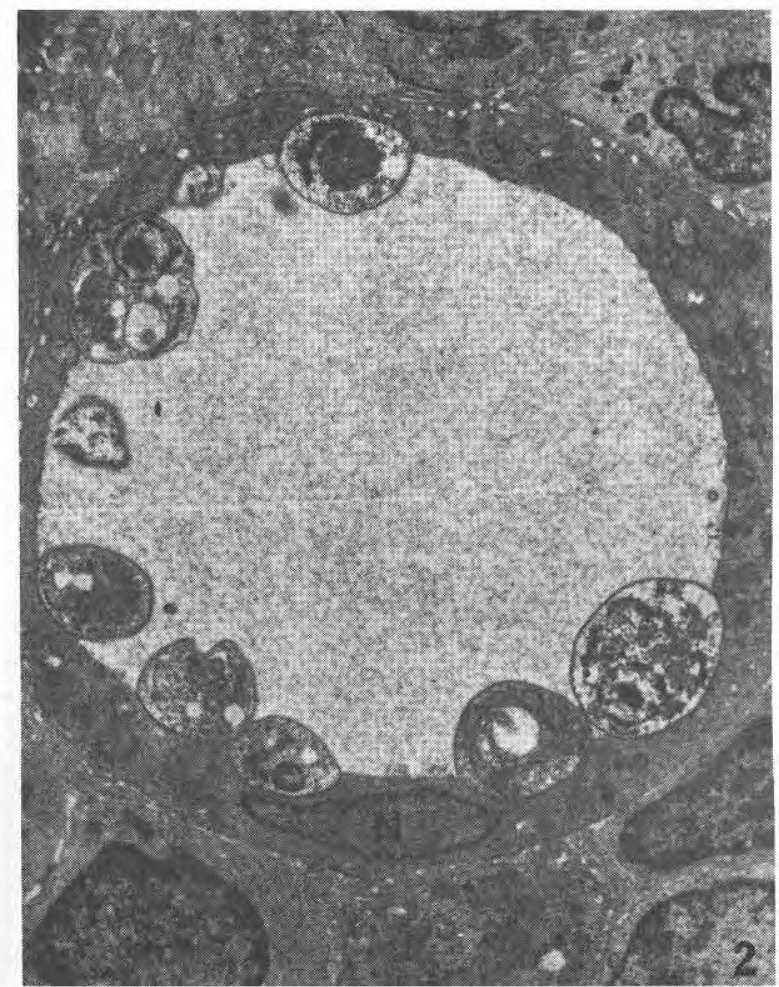

Fig. 2. El núcleo (N) y otros organelos de este macrófago están rechazados por la gran vacuola (fagolisosoma) que contiene 8 leishmanias que no presentan signos de alteración por el fagocito. $4.750 \mathrm{X}$. Leishmaniasis difusa.

pero se sabe que los animales que en otros países son reservorios de la enfermedad existen en nuestro medio, lo mismo que los vectores. Se ha demostrado, en cambio, que el perro es el reservorio en los focos estudiados de leishmaniasis visceral (7). El exterminio de estos perros enfermos constituyen un paso esencial en el control de esta zoonosis.

\section{CLASIFICACION}

Las leishmanias pertenecen al Phylum Protozoa (unicelulares), clase Mastigophora (poseen flagelo) Orden Kinetoplastida (Kinetoplasto: mitocondria especial con ADN) y género Leishmania (Leishman demostró los protozoarios en un paciente con Kala-azar 


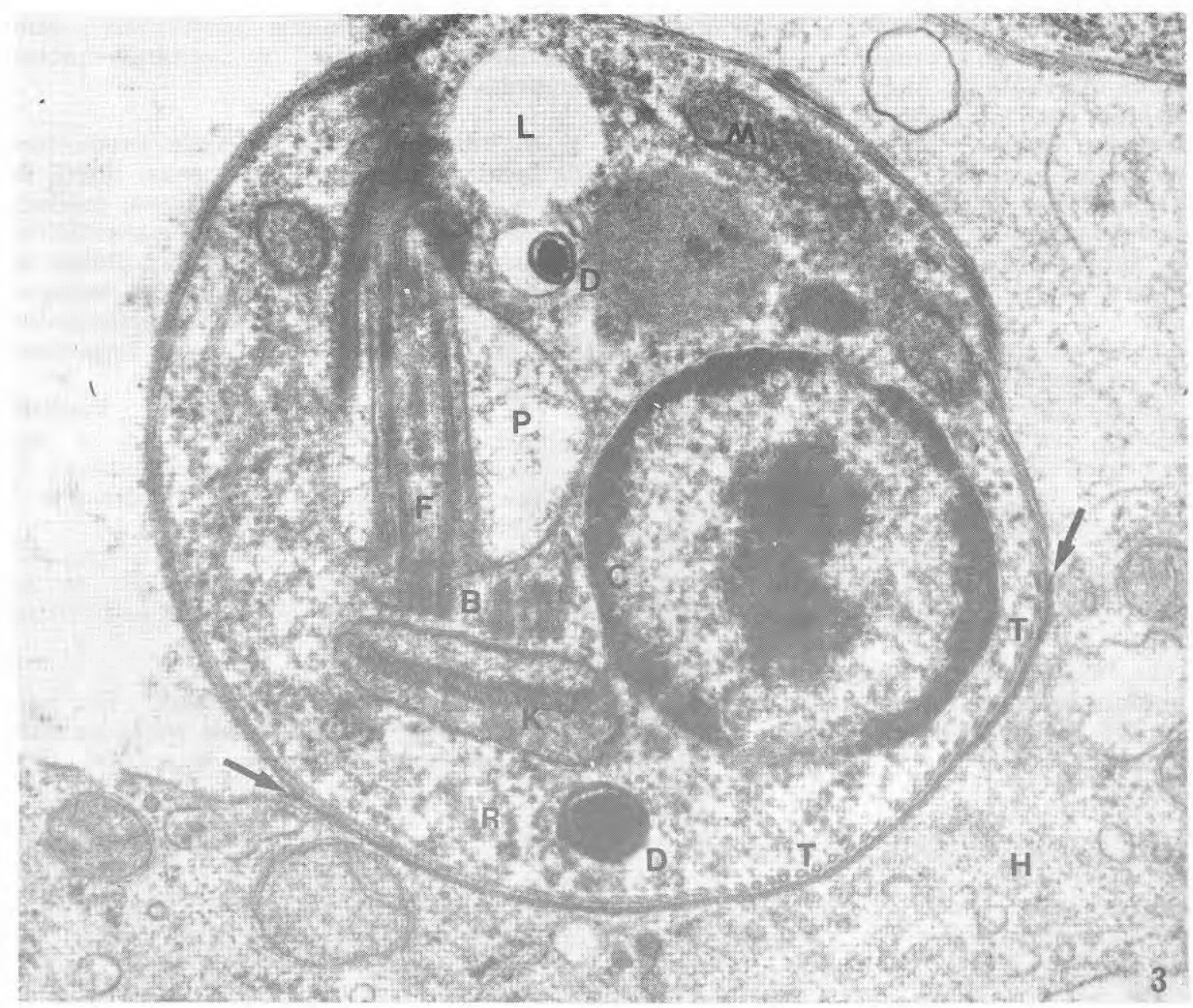

Fig. 3. Ilustra los organelos del amastigote: $\mathrm{C}$ : cromatina nuclear; $\mathrm{N}$ : nucleolo; (cariosoma); K: kinetoplasto; $\mathbf{M}$ : mitocondria; D : cuerpos densos, probablemente lisosomas; B : centriolos ( blefaroplasto ); su duplicidad sugiere que el parásito se iba a dividir. F : flagelo, en corte longitudinal. P: hendidura flagelar; T: microtúbulos, que sólo se aprecian nítidamente en el corte transversal. $\mathbf{R}$ : ribosomas. $L$ : estructura clara que sugiere una vacuola lipídica. Las flechas indican la unidad de membrana que se adosa íntimamente a la del macrófago $(\mathrm{H})$ que contiene el parásito. 46.000 X. Leishmaniasis difusa.

en 1903). Se aceptan varios grupos o complejos para las especies, así: $2-4,8)$.

Complejo Leishmania mexicana: (Leishmaniasis Cutánea Americana).

1. L. mexicana mexicana: La cepa tipo, productora de la úlcera de los "chicleros" y otras lesiones cutáneas en Yucatán, Belize y Guatemala. Su principal vector es Lu. olmeca olmeca y los reservorios son roedores selváticos pequeños. Crece fácilmente en el cultivo e inoculada al hámster le origina lesiones extensas, en pocas semanas, con metástasis cutáneas y viscerales.

2. L. mexicana pifanoi: Productora de leishmaniasis difusa en Venezuela, en personas con defectos de la inmunidad celular, específica ante el parásito. 
3. L. mexicana amazonensis: Descrita en la región amazónica brasileña. Posiblemente no sea diferente de L. m. pifanoi. Se asocia también con un porcentaje alto de leishmaniasis difusa, en los huéspedes con inmunidad celular defectuosa ante el parásito. Los reservorios principales son pequeños roedores (Proechimys) y el vector, Lu. flaviscutellata. Esta especie existe en Colombia.

4. L. mexicana garnhami: Descrita en 1979 como L. garnhami en los Andes venezolanos, a alturas entre 800 y $1.800 \mathrm{~m}$, asociada con lesiones cutáneas humanas y con Lu. townsendi como vector.

5. L. mexicana venezuelensis: Aislada de lesiones cutáneas humanas en el Estado Lara, (Venezuela) y caracterizada mediante isoenzimas y anticuerpos monoclonales.

6. L. mexicana aristedesi: Aislada en Panamá de pequeños marsupiales y roedores. No se ha visto en lesiones humanas todavía.
Complejo Leishmanis braziliensis (Leishmaniasis cutánea y cutáneo-mucosa americana).

1. L. braziliensis: braziliensis: Productora de lesiones cutáneas y mucosas; difícil de cultivar y de mantener en cultivo; produce lesiones de lenta evolución, no metastásicas y poco prominentes en el hámster. Didelphys marsupialis (fara, zarigueya) y roedores pequeños, son sus reservorios principales. Encontrada desde Belize a la Argentina.

2. L. braziliensis panamensis: Produce lesiones cutáneas, que tienden a ser linfangíticas; crece mejor en el cultivo y da lesiones más prominentes en el hámster; C. hoffmanni es su huésped natural, en el cual abunda en la piel y en las vísceras, sin producirle lesiones. Lu. trapidoi se ha encontrado infectado en Colombia por este parásito (1).

3. L. braziliensis guyanensis: Es muy semejante a $L$. b. panamensis. No se ha visto que produzca lesiones mucosas. Sus

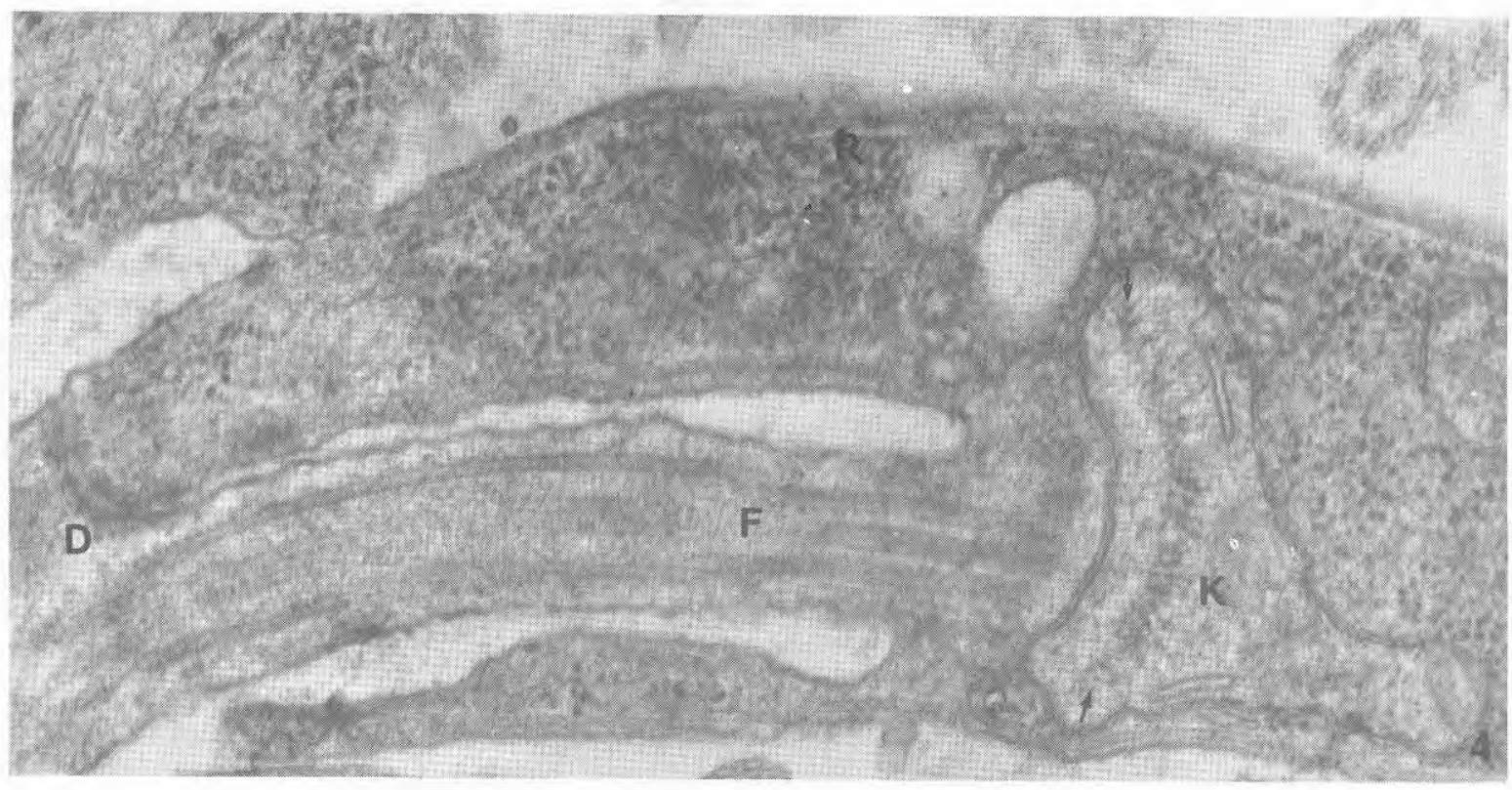

Fig. 4. Extremo anterior de un promastigote. F: flagelo en corte longitudinal. D : unión desmosónica entre la membrana flagelar y la citoplasmática; $\mathbb{R}$ : ribosomas; $\mathrm{K}$ : kinetoplasto con sus filamentos de ADN (flechas) y crestas mitocondriales $50.000 \mathrm{X}$. 


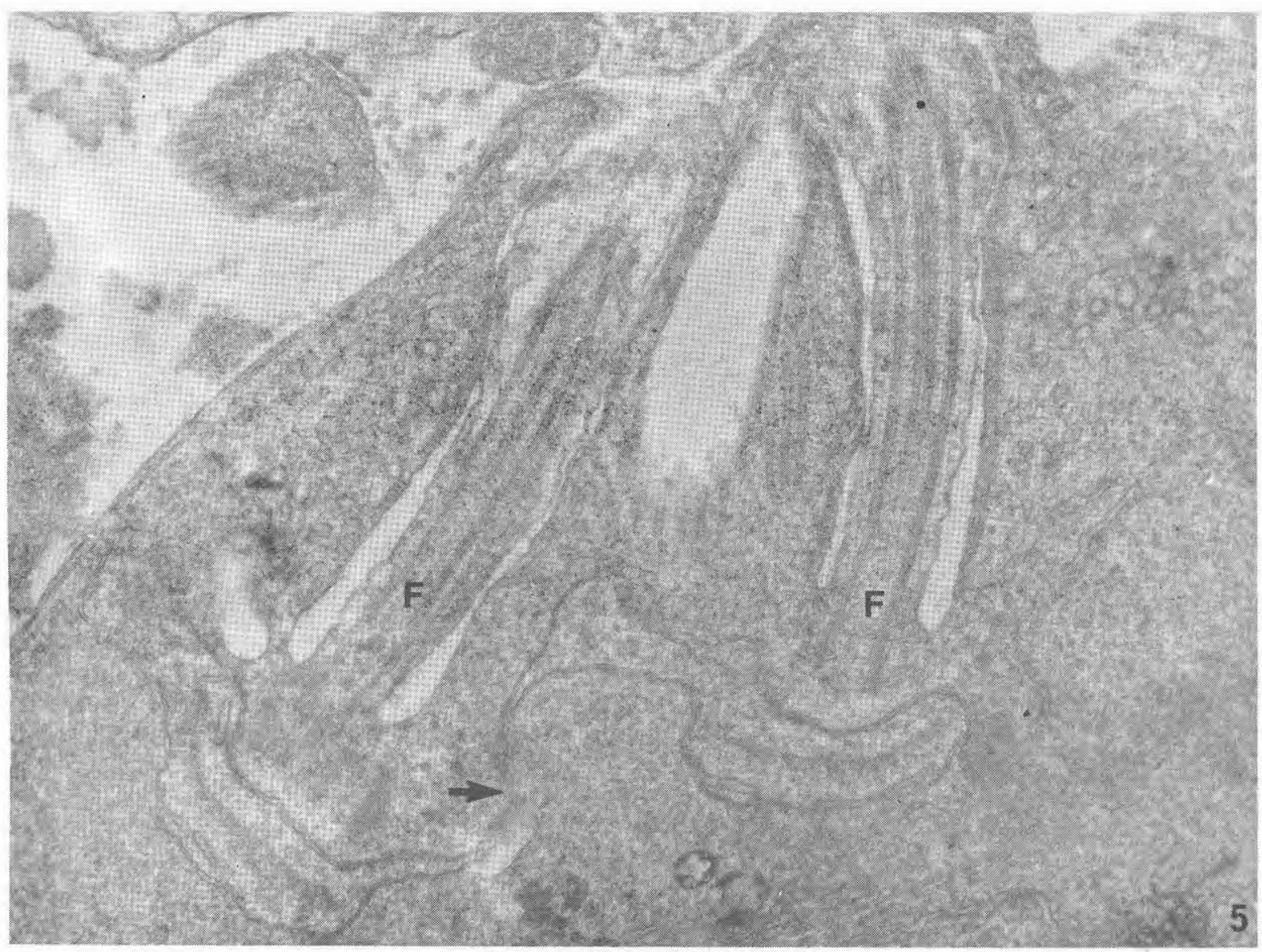

Fig. 5. Promastigote en división. Se aprecia el doble flagelo (F) y la escisión del kinetoplasto (flecha). $36.000 \mathrm{X}$.

reservorios son mamíferos edentados $C$. didactylus: perezoso y Tamandua tetradactyla: oso hormiguero. Distribuída en las Guyanas, Surinam y el Estado de Pará en el Brasil, no sería rara su presencia en Colombia.

4. L. braziliensis peruviana: Produce lesiones cutáneas ("uta") en los Andes peruanos y argentinos a alturas entre 900 y 3.000 metros. El perro es el reservorio y Lu. verrucarum el vector.

Complejo Leishmania donovani (Lehishmaniasis Visceral).

1. L. donovani donovani: Produce el kalaAzar en el Asia; la transmisión de la enfermedad es de hombre a hombre.
2. L. donovani infantum: Produce la leishmaniasis visceral de los países del Mediterráneo. Posiblemente, este parásito se importó a América en los perros infectados que venían con los conquistadores.

3. L. donovani chagasi: Produce la leishmaniasis visceral americana. El perro es su principal huésped y Cerdocyon thous (zorro) su reservorio salvaje (2). En los focos colombianos de leishmaniasis visceral, $\mathrm{Lu}$. longipalpis es el vector (7).

Otras cepas del Viejo y Nuevo Mundo que producen lesiones cutáneas son:

L. tropica major, euroasiática: Leishmaniasis cutánea. 

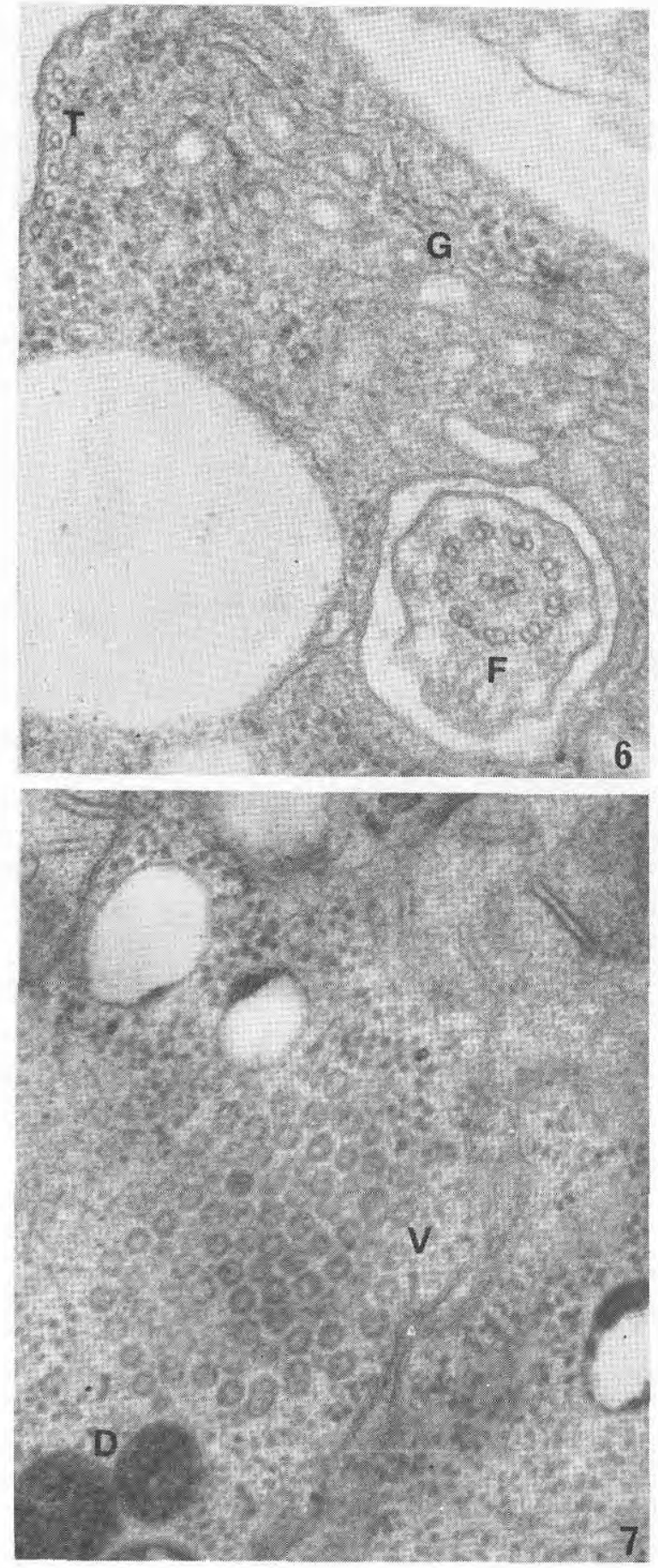

Fig. 6 y 7 . Cortes del extremo anterior de un promastigote. G : aparato de Golgi; $T$ : microtúbulos ; $F$ : flagelo en corte transversal; V : vesículas golgianas; $D$ : cuerpos densos (lisosomas?). $60.000 \mathrm{X}$.
L. tropica minor, euroasiática: Leishmaniasis cutánea.

L. etiópica, africana: Leishmaniasis difusa.

L. isabela, no tipificada aún, productora de leishmaniasis difusa en República Dominicana (9).

Esta clasificación proviene del empleo de varios criterios $(2-4,8)$ que incluyen desde luego los patrones clínicos y geográficos junto con métodos de laboratorio como el comportamiento del parásito en el cultivo y en la inoculación del hámster (Mesocricetus auratus) (Fig. 8), la densidad del ADN del kinetoplasto, los serotipos, que determinan la excreción de substancias al medio de cultivo por los promastigotes, la identificación en estas formas de diversos tipos de iso-enzimas, como fosfatasa ácida, malato deshidrogenasa, glucosa-6 fosfatodeshidrogenasa, fosfoglucomutasa (PMG), glucosa-fosfato isomerasa (GPI), alaninoaminotransferasa (AAT), el uso de anticuerpos monoclonales y la localización de los promastigotes en el intestino del vector.

La tipificación es muy importante como método de investigación epidemiológica para determinar áreas de distribución de las especies, para encontrar especies nuevas, para correlacionar los hallazgos en los pacientes, los reservorios y los vectores e incluso para definir normas de tratamiento. A su vez, el pronóstico, el curso y el tipo de enfermedad varía con las especies del parásito. Así, es posible que en América, sólo las cepas de $L$. braziliensis braziliensis produzcan lesiones mucosas (4); las cepas de L. $m$. pifanoi y $L \mathrm{~m}$. amazonensis se asocian con las lesiones de leishmaniasis difusa en los huéspedes con inmunidad celular defectuosa (2).

\section{LEISHMANIASIS EN COLOMBIA}

Se conoce desde la época precolombiana y ha despertado el interés médico desde 1872 cuando Josué Gómez identificó como "botón de Alepo" la enfermedad que padecía un niño de 11 años, que tenía 3 nódulos en su mejilla y que las gentes de Vélez y el Valle de Tenza nombraban como "bubón de Vélez", "marranas" o "puercas" (10). En una 


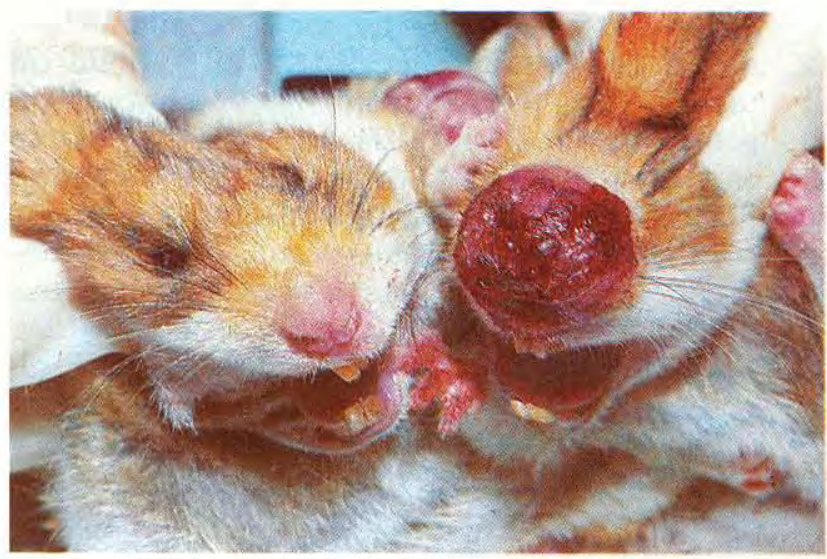

Fig. 8. Hamster inoculado 45 días antes con macerado de una lesión cutánea de leishmaniasis difusa. Compárese con el animal control.

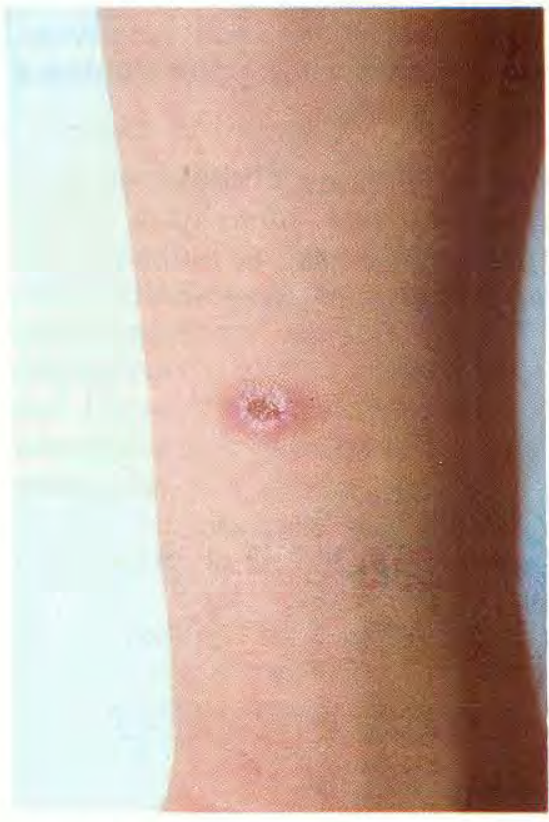

Fig. 9. Pápula con ulceración incipiente. Un mes de evolución.

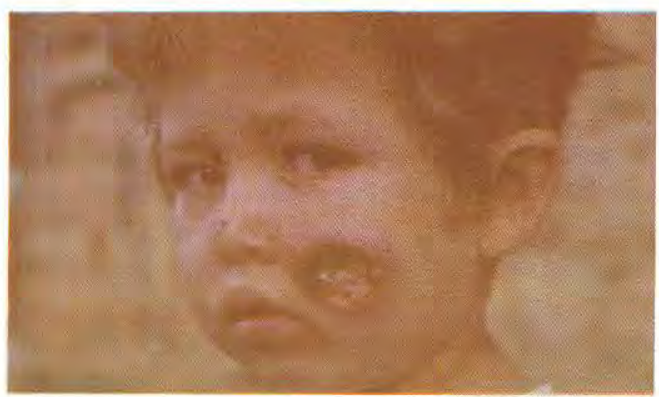

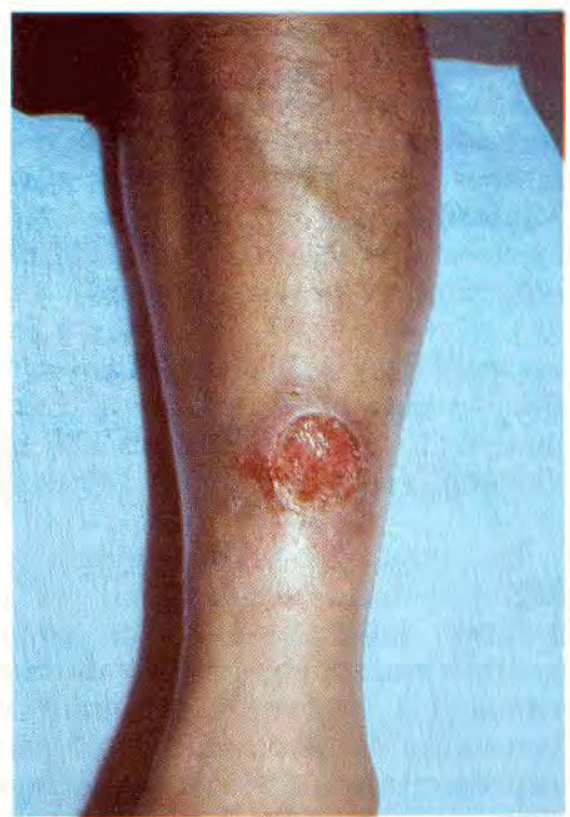

Fig. 11. Ulcera típica en la pierna de una mujer. Tres meses de evolución.

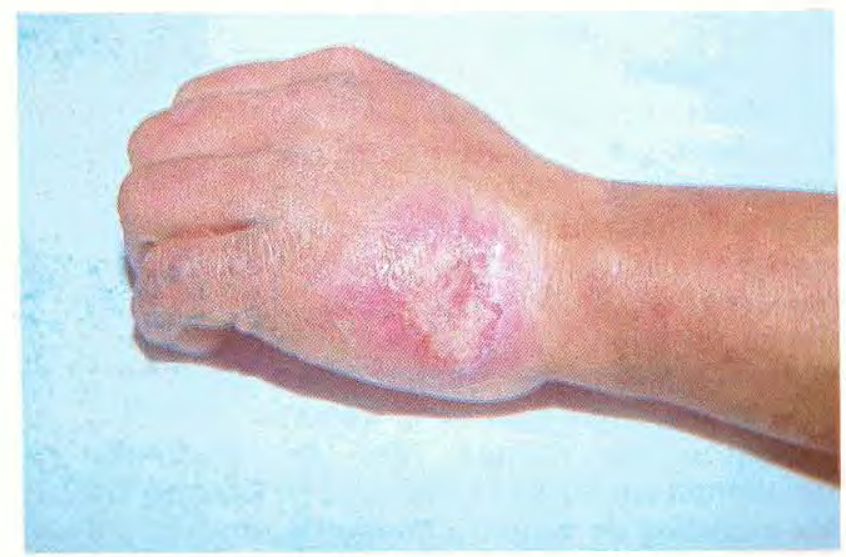

Fig. 12. Ulcera superficial rodeada por una amplia zona eritematosa, muy infiltrada.

Fig. 10. Extensa úlcera de 2 meses de evolución. Paciente de la M esa (Cundinamarca). 
revisión de la enfermedad en Colombia, de 1889 a 1980 (11), se contabilizaron 1.865 casos, distribuídos en la mayor parte del territorio nacional, por debajo de los 2.300 metros de altura sobre el nivel del mar. Mediante un diagnóstico más estricto, haciendo obligatoria la notificación de la enfermedad y suministrando gratuitamente el Glucantime (R), Corredor y Ronderos (12) encontraron 739 casos nuevos de leishmaniasis cutánea en 1981 y 1.076 en 1.982 . De la misma forma detectaron 52 casos de L. visceral en 1981 y 55 en 1982 (12).

La tasa de leishmaniasis cutánea en algunas zonas endémicas es de 2.4 por 100.000 habitantes y en pocos años es posible reunir casuísticas de centenares de casos (13). La forma cutánea pura es la más frecuente. En promedio, las formas mucosas representan el 25\% (11). La forma visceral es cada vez más frecuente (7). En el INS hemos estudiado dos pacientes con leishmaniasis anérgica tegumentaria difusa, entidad que también se menciona en otros trabajos $(11,13)$.

La tipificación de especies hasta ahora comienza en Colombia. Además de L.b. braziliensis y de L. chagasi, es segura la presencia de L.b. panamensis; cuadros clínicos como la "úlcera de los chicleros", sugieren la presencia de $L$. mexicana. Nuestro estudio de un paciente con leishmaniasis difusa (Figs. 1-3) reveló un parásito con características morfológicas, de cultivo y de comportamiento en el hámster como los descritos en cepas de $L$. mexicana amazonensis. La caracterización precisa de las especies de nuestro medio es un objetivo de diferentes grupos de trabajo y no es aventurado afirmar la tipificación de nuevas variedades en el futuro próximo.

\section{LEISHMANIASIS CUTANEA}

Las cepas de leishmania presentes en Colombia y en los países americanos con leishmaniasis autóctona (todos, con excepción de Canadá, Uruguay y Chile), producen lesiones cutáneas de un enorme pleomorfismo clínico. Las lesiones básicas pueden ser pápulas, nódulos y placas infiltradas, costrosas, indoloras, localizadas en cual- quier parte del cuerpo, con excepción del cuero cabelludo (Figs. 9-18). El período de incubación, variable, es comúnmente de 3 semanas. La pápula se ulcera a las pocas semanas de enfermedad y se extiende periféricamente hasta alcanzar varios centímetros de diámetro, con poca profundidad (Figs. 10-13). Las lesiones pueden ser únicas o múltiples, de distribución irregular o siguiendo un trayecto linfático. (Figs. 16-17). La úlcera leishmaniásica es típica por su borde firme, acordonado, levantado y por su fondo granuloso y limpio (Figs. 10-11). Puede cubrirse de una gruesa costra carnoide que es necesario remover para poder ver la úlcera típica. A veces hay formas ulcerocostrosas sin mayor apariencia acordonada del borde activo (Figs. 14-15). Las lesiones del pabellón auricular (úlcera de los chicleros) son erosivas, mutilantes, persistentes y muy resistentes a los tratamientos (Fig. 18).

La diversidad de formas clínicas es muy grande: incluyen formas ulceradas nodulares, verrucosas, lupoides, papulosas, linfangíticas, que obligan al diagnóstico diferencial con esporotricosis, cromomicosis, paracoccidioidomicosis, TBC verrucosa, carcinomas, sarcoidosis, etc. En general, las úlceras cutáneas curan espontáneamente entre los 5 y los 12 meses de iniciadas. Pueden, no obstante, prolongarse por años. Hemos visto un grupo de niños infectados probablemente con una cepa de L. braziliensis braziliensis en quienes se presentó curación espontánea entre los 5 y los 7 meses de iniciada la enfermedad.

\section{LEISHMANIASIS MUCOSA}

Es producida por L.b. braziliensis y se llama espundia y leishmaniasis mucocutánea americana, pues sólo ocurre en este continente, desde Honduras a la Argentina (4). En Africa se ha visto una enfermedad semejante que se ha relacionado con una forma clínica especial de Kala-Azar (14). En poco más de 400 biopsias de leishmaniasis estudiadas en el INS en los últimos 10 años, la leishmaniasis mucosa representa un $15 \%$.

Las lesiones mucosas afectan con mayor frecuencia la nariz y la orofaringe (Fig. 19), 


\section{LEISHMANIASIS}

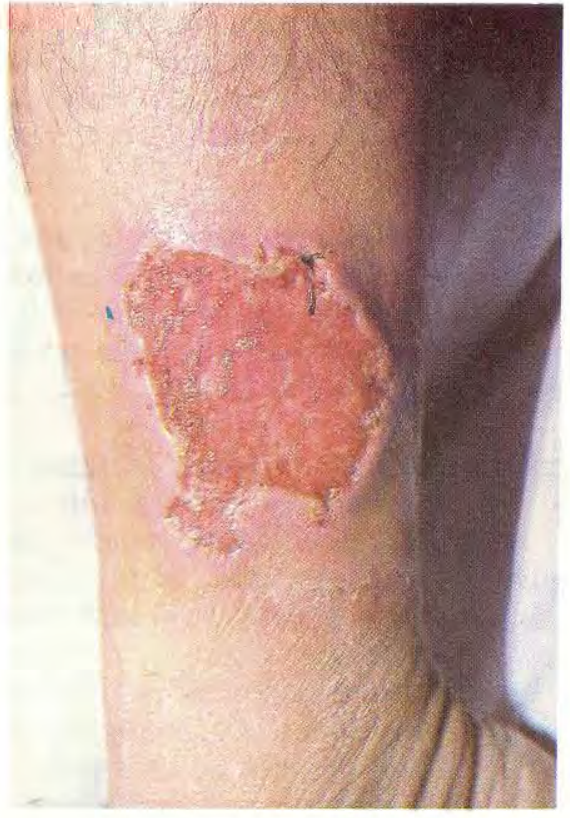

Fig. 13. Ulcera menos típica por su extensión y poca prominencia del borde.

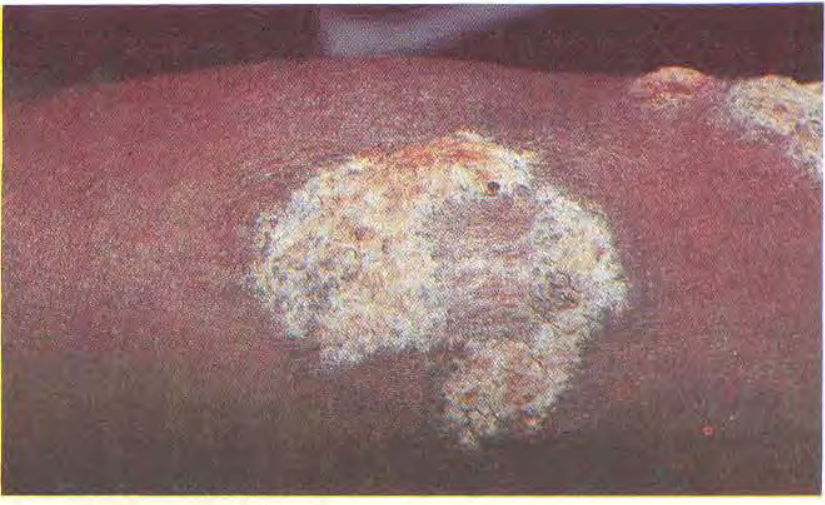

Fig. 15. Placas costrosas e hiperqueatósicas del brazo, que se prestan a diagnóstico diferencial con cromomicosis y esporotricosis.

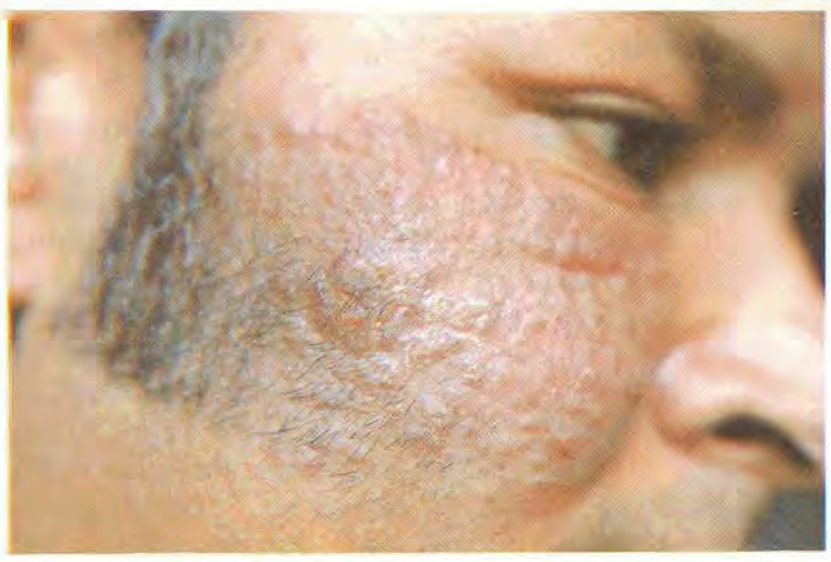

Fig. 14. Extensa placa micronodular de 4 meses de evolución. La biopsia fue muy rica en amastigotes y se requirieron 140 ampollas de Glucantime para la curación total.

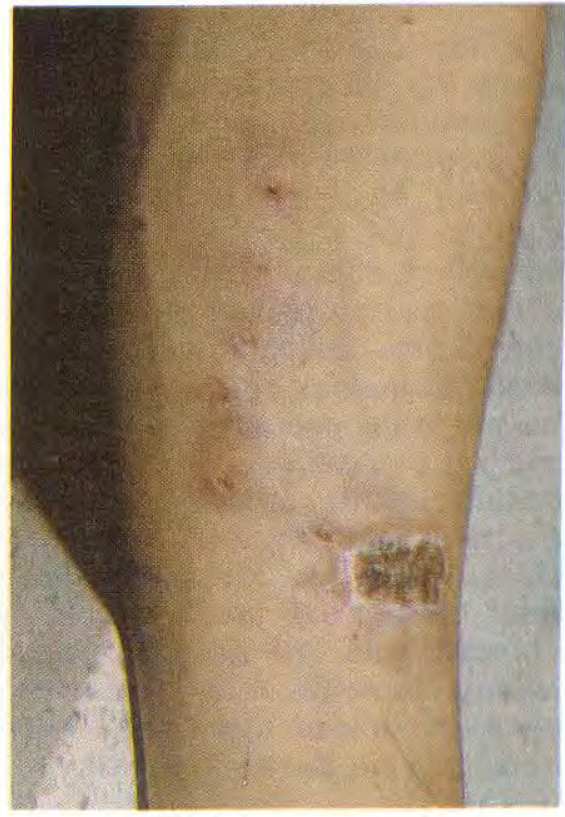

Fig. 16. Forma linfangítica a partir de una úlcera mayor, inicial. Dos meses de evolución. La biopsia mostró granulomas centrados por necrosis extensa, semejante a la TBC. N o se vieron leishmanias. La leishmanina fue positiva y el enfermo curó con Glucantime. 
pero pueden comprometer cualquier mucosa. Tienen las siguientes características:

1. Pueden ocurrir por extensión directa desde la piel a la mucosa vecina, cuando la inoculación ocurrió en un sitio que así lo facilite como en la columela, la punta nasal o el labio superior (Fig. 20).

2. Pueden ser concomitantes con una úlcera cutánea a distancia.

3. Pueden ocurrir meses o años después de la curación espontánea o por tratamiento insuficiente de una úlcera leishmaniásica cutánea. En nuestra experiencia hay casos razonablemente estudiados, con aparición de la lesión mucosa nasal 30 años después de una úlcera en la pierna. Los amastigotes se han demostrado en la mucosa nasal sana de pacientes con úlceras recientes (15). Allí permanecen en equilibrio inmunológico con el huésped durante años, o son erradicadas mediante el tratamiento. Las condiciones que inducen su proliferación y la producción de enfermedad mucosa son poco conocidas. Se han sugerido condiciones debilitantes como la TBC y la desnutrición (16). El trauma es un factor importante. Walton ha visto que el trauma cutáneo en piel sana, en pacientes con úlceras leishmaniásicas, induce lesiones leishmaniásicas en ese sitio. Hemos visto en un paciente procedente de Muzo, con úlceras muy extensas en una pantorrilla, el desarrollo de lesiones mucosas 5 meses después de recibir una inyección de Decadrón I. M., formulada por un médico, que creyó así acelerar la mejoría ya obtenida con 20 ampollas de Glucantime. Indudablemente la relación huéspedparásito ofrece aquí características inmunológicas de particular interés.

4. En más del $90 \%$ de los pacientes con leishmaniasis mucosa existe una cicatriz cutánea leishmaniásica previa (17). Es pues obligatoria la búsqueda de esta cicatriz para coadyuvar al diagnóstico (Fig. 21).

5. Las lesiones mucosas comienzan con secreciones purulentas y sensación de obstrucción nasal que progresa a la ulceración franca con destrucción del tabique, como consecuencia de los cambios inflamatorios y vasculares. La extensión al labio superior y la nasofaringe es común. Pueden afectarse la laringe, la tráquea y los bronquios.

6. La fetidez y la disfonía son comunes. Pueden presentarse infecciones secundarias respiratorias y meníngeas graves. La dificultad para alimentarse origina caquexia en muchos de estos pacientes (Fig. 19).

7. Otras enfermedades pueden originar cuadros de infiltración, u ulceración y destrucción nasofaríngea, tales como la lepra lepromatosa, el escleroma, el pian, la paracoccidioidomicosis y diversas lesiones tumorales y vasculíticas. En nuestra experiencia la leishmaniasis mucosa es la causa más frecuente de esta patología en nuestro medio, pero siempre se deben realizar los procedimientos pertinentes para un diagnóstico diferencial adecuado, que además de la clínica y la epidemiología incluyen la biopsia, los cultivos, las intradermorreacciones (Fig. 22) y los títulos de anticuerpos.

8. La leishmaniasis mucosa no cura espontáneamente y es rebelde al tratamiento, que debe ser vigoroso y bien vigilado (18). Las recidivas son frecuentes. Puede tener un curso muy prolongado y dejada a su evolución natural, es una enfermedad fatal.

\section{LEHISMANIASIS VISCERAL}

En América, es producida por L. chagasi y transmitida por Lu. longipalpis. El primer caso en Colombia se publicó en 1944 (19) y sólo en 1962 aparecieron nuevos pacientes (7). Hoy se han comprobado más de 120 casos, con una localización geográfica precisa, siguiendo las tierras cálidas y secas del alto Magdalena $(7,20)$. Ospina Pérez, Nilo, Tocaima, Agua de Dios, Jerusalén, Guataquí, Ricaurte, Pulí, La Peña (Cundinamarca); Melgar, Natagaima, Icononzo, Purificación, Prado, Saldaña, Guamo, Espinal, Chaparral, Cunday, Carmen de Apicalá, Coyaima, Coello, Ataco (Tolima); Neiva, Aipe, Palermo, Baraya, Villa Vieja, Tesalia, Paicol, Campoalegre (Huila); Lebrija, San Andrés, San Gil, Girón, Barran- 


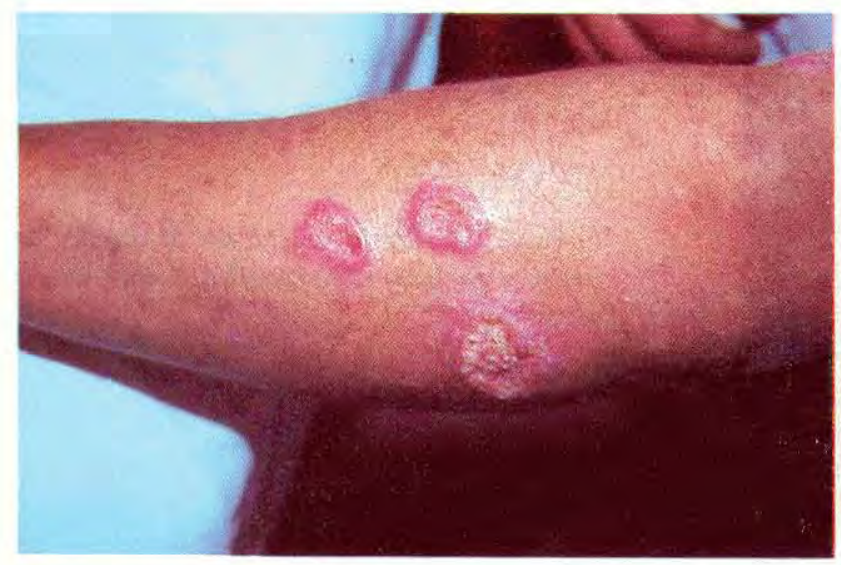

Fig. 17. Ulceras que pueden reflejar una propagación linfangítica o picaduras infectantes múltiples.

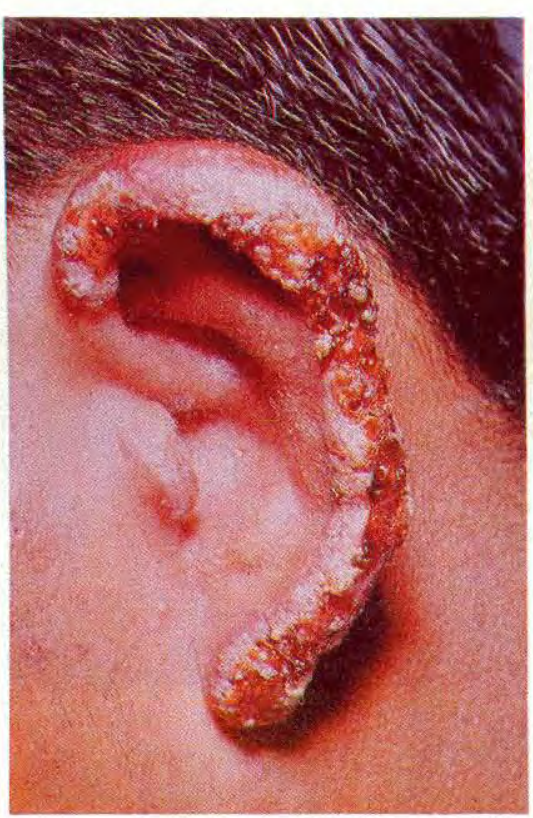

Fig. 18. Ulcera de los chicleros. Esta clínica ha hecho sugerir la presencia de $L$ mexicana en el país.

Fig. 19. Paciente caquéctico con disfonía y destrucción extensa del tabique nasal y el labio superior. La impresión clínica fue de carcinoma escamocelular. No había cicatriz cutánea, El Montenegro fue negativo pero la biopsia mostró los amastigotes. Enfermedad de 2 años de evolución. Nótese el área eritematosa, infiltrada, de la periferia de la lesión.

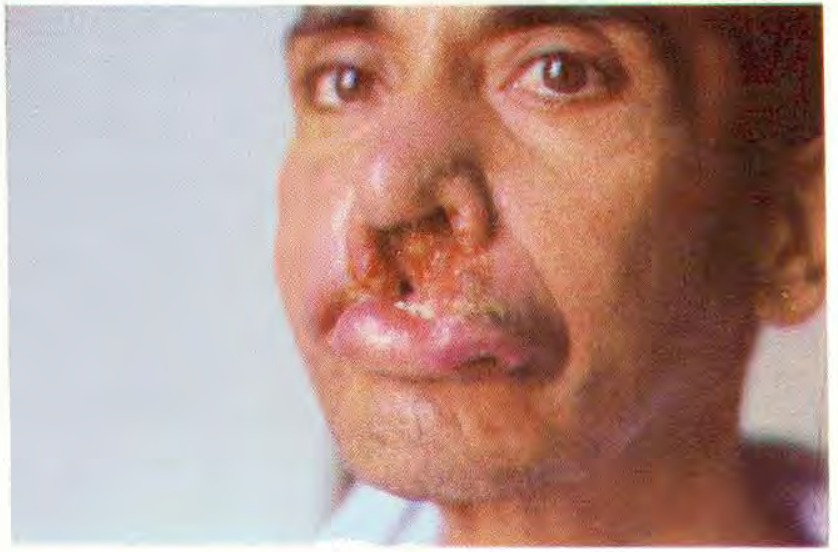




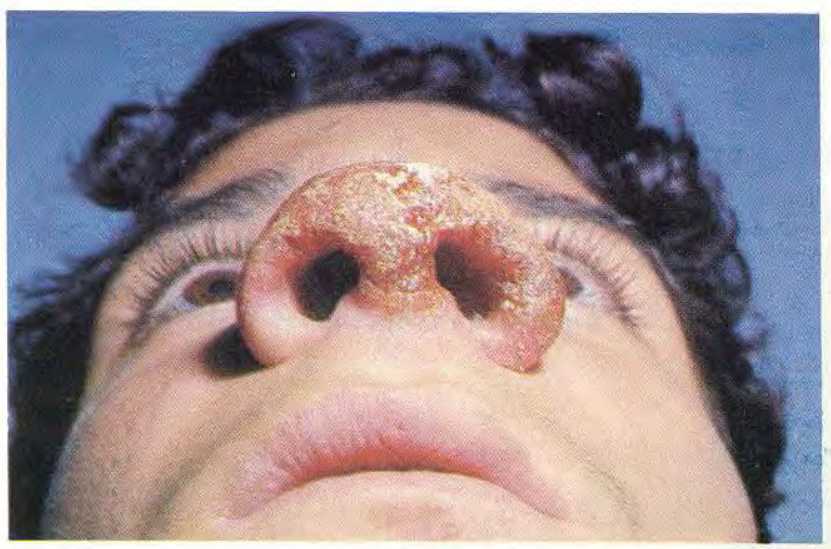

Fig. 20. Placa nasal de 2 meses de evolución que comenzaba a invadir la mucosa.

Fig. 21. Cicatriz de úlcera leishmaniásica que curó espontáneamente.

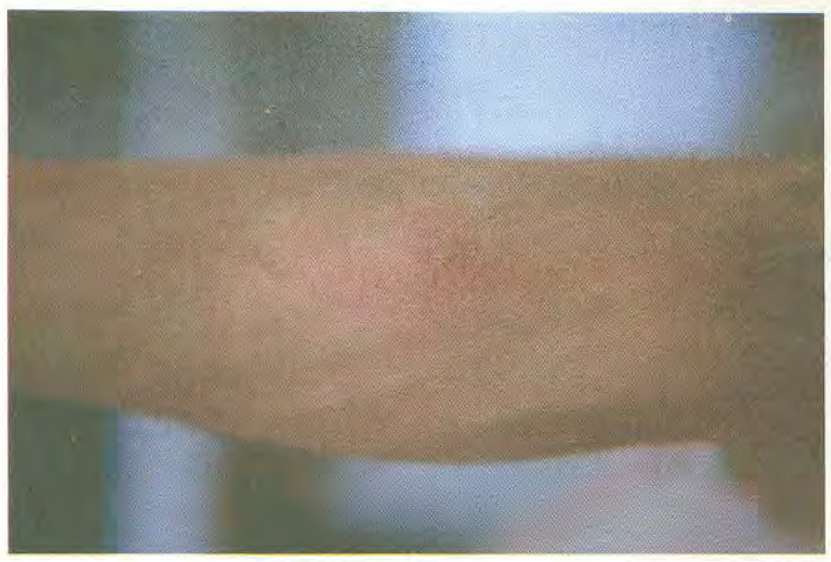

Fig. 22. Reacción positiva a la leishmanina. Este paciente tenía perforación del tabique nasal e infiltración granulomatosa de la faringe. Había sido tratado durante 5 afios como escleroma. 
cabermeja (Santander); Carmen de Bolívar (Bolívar); San Andrés (Córdoba); Ovejas, Morroa, Sampués (Sucre); Barrancas, San Juan del Cesar (Guajira), son los municipios en donde hasta ahora se ha encontrado la enfermedad $(7,20)$, que predomina en niños menores de 5 años, en quienes debe sospecharse ante la presencia de enfermedad febril prolongada con hepato, espleno y adenomegalias, pancitopenia, emaciación e hipergamaglobulinemia. Los detalles epidemiológicos del primer caso colombiano de leishmaniasis visceral, diagnosticado en una niña fallecida en San Vicente de Chucurí (Santander), se discutirán en otro artículo de esta revista.

La leishmaniasis visceral en Colombia pasó del diagnóstico ocasional por viscerotomía, al descubrimiento de pequeños focos y finalmente a la detección de amplias áreas con buen número de casos que la convirtieron en un problema nacional de salud pública, afrontado por el Ministerio de Salud y el Instituto Nacional de Salud con programas de diagnóstico temprano de casos nuevos y mediante campañas de instrucción a los médicos y paramédicos, lo mismo que a las comunidades afectadas.

\section{PATOLOGIA}

La histopatología de la leishmaniasis varía con muchos factores entre los que cabe destacar el agente etiológico, el tiempo de evolución de las lesiones, la ulceración, el tratamiento previo y la infección secundaria.

Las lesiones ulcerosas típicas, que son las más biopsiadas, muestran una hiperplasia pseudoepiteliomatosa severa e infiltrados dérmicos granulomatosos, con histiocitos vacuolados o epitelioides y un número variable de células gigantes (Figs. 23-30). No hay granulomas centrados por polinucleares, propios de los hongos y el número de plasmocitos es siempre muy aparente. Los linfocitos son también abundantes. En la mitad de 400 casos de leishmaniasis pudimos demostrar el parásito, localizado dentro de vacuolas en los macrófagos, estableciendo así un diagnóstico concluyente de la entidad. La demostración del parásito en las biopsias varía mucho según las casuísticas. Esta disparidad se debe no sólo al agente causal y al tiempo de evolución de la enfermedad, sino al número de cortes examinados y al tiempo dedicado al estudio de los mismos, incluyendo objetivo de inmersión. En general, después de 5 semanas de enfermedad las posibilidades de demostrar el parásito en las biopsias disminuyen, pero las excepciones son numerosas. No hay un estudio controlado en nuestro medio que correlacione la especie de parásito con la facilidad de demostración del mismo en los tejidos, pero es conocido que las cepas de L. braziliensis braziliensis son más difíciles de demostrar. La biopsia es muy útil porque permite un diagnóstico diferencial y porque es posible sugerir la entidad y encausar un tratamiento, aunque no se demuestren los parásitos.

La leishmaniasis visceral, como forma anérgica que es de la enfermedad, presenta

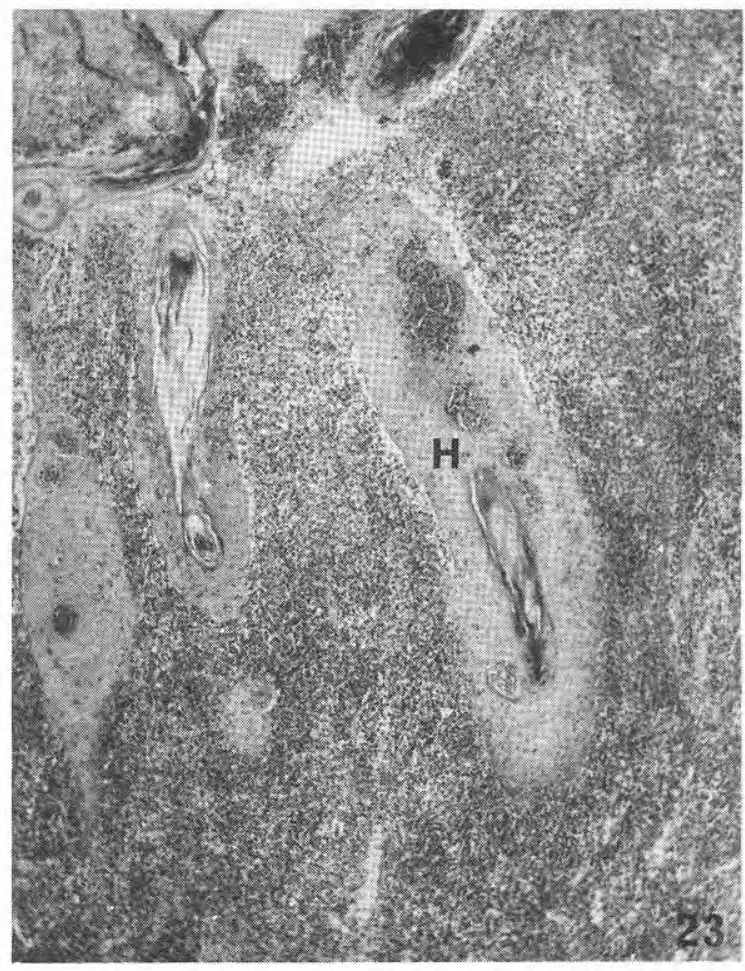

Fig. 23. Leishmaniasis cutánea. Aspecto panorámico. Hiperplasia epitelial $(\mathrm{H})$ e infiltrado dérmico masivo. HE. $40 \mathrm{X}$. 


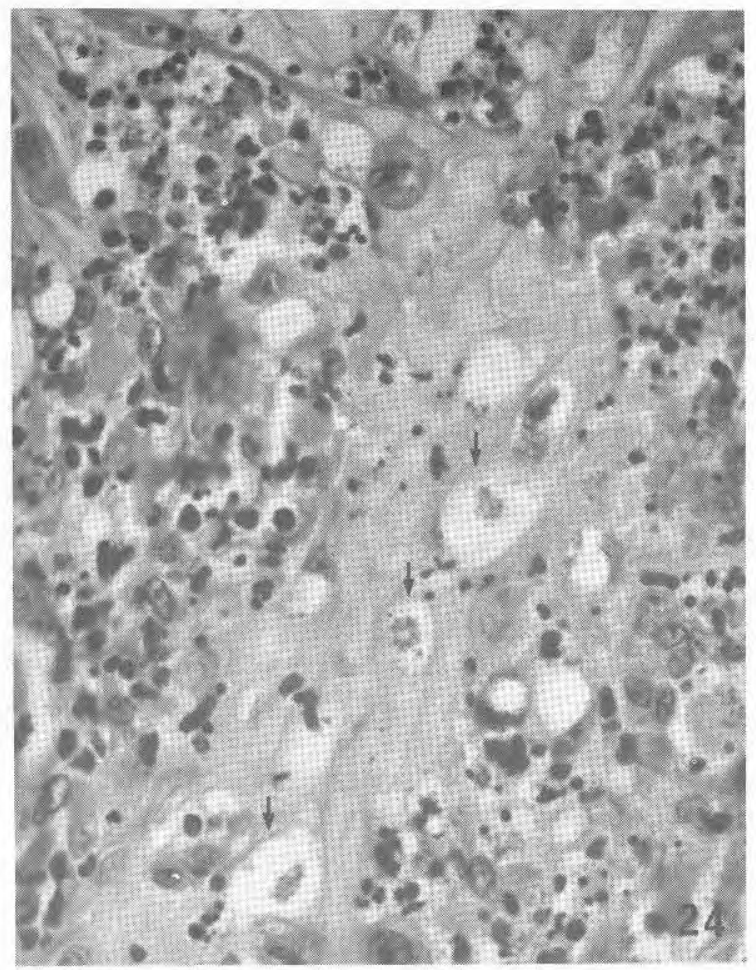

Figs. 24-26. Hiperplasia epitelial e infiltrado inflamatorio de las papilas, con algunos polinucleares que no forman microabscesos. Las flechas indican queratinocitos con amastigotes, que se aprecian a mayor aumento en la figura 25. La hiperplasia pseudoepiteliomatosa de la figura 26 puede confundirse con un carcinoma escamocelular. El desarrollo de cáncer sobre una lesión leishmaniásica, aunque informado, es excepcional. Figura 24. HE. 400 X. Figura 25. HE. 1.000 X. Figura 26. HE. 160 X.
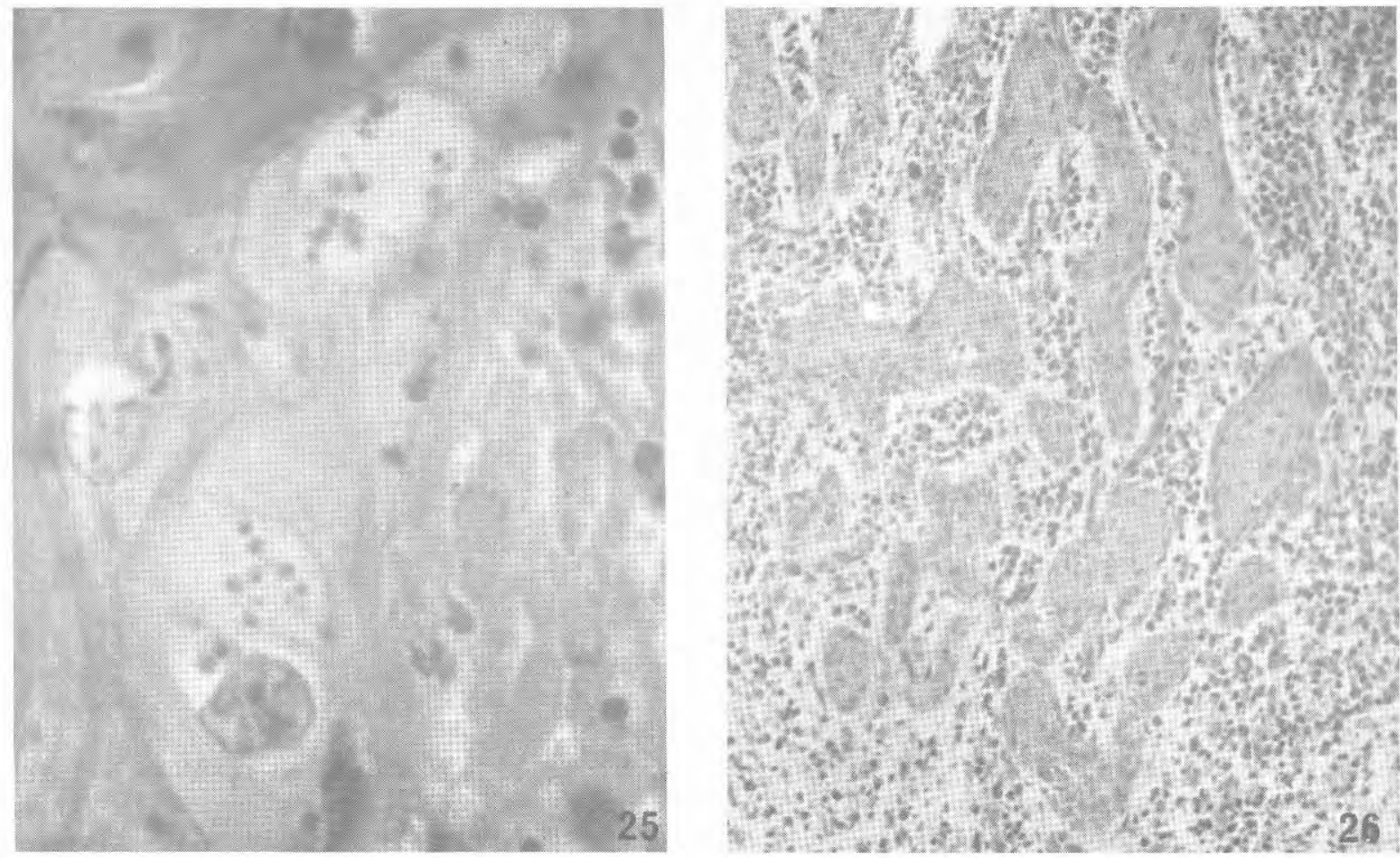

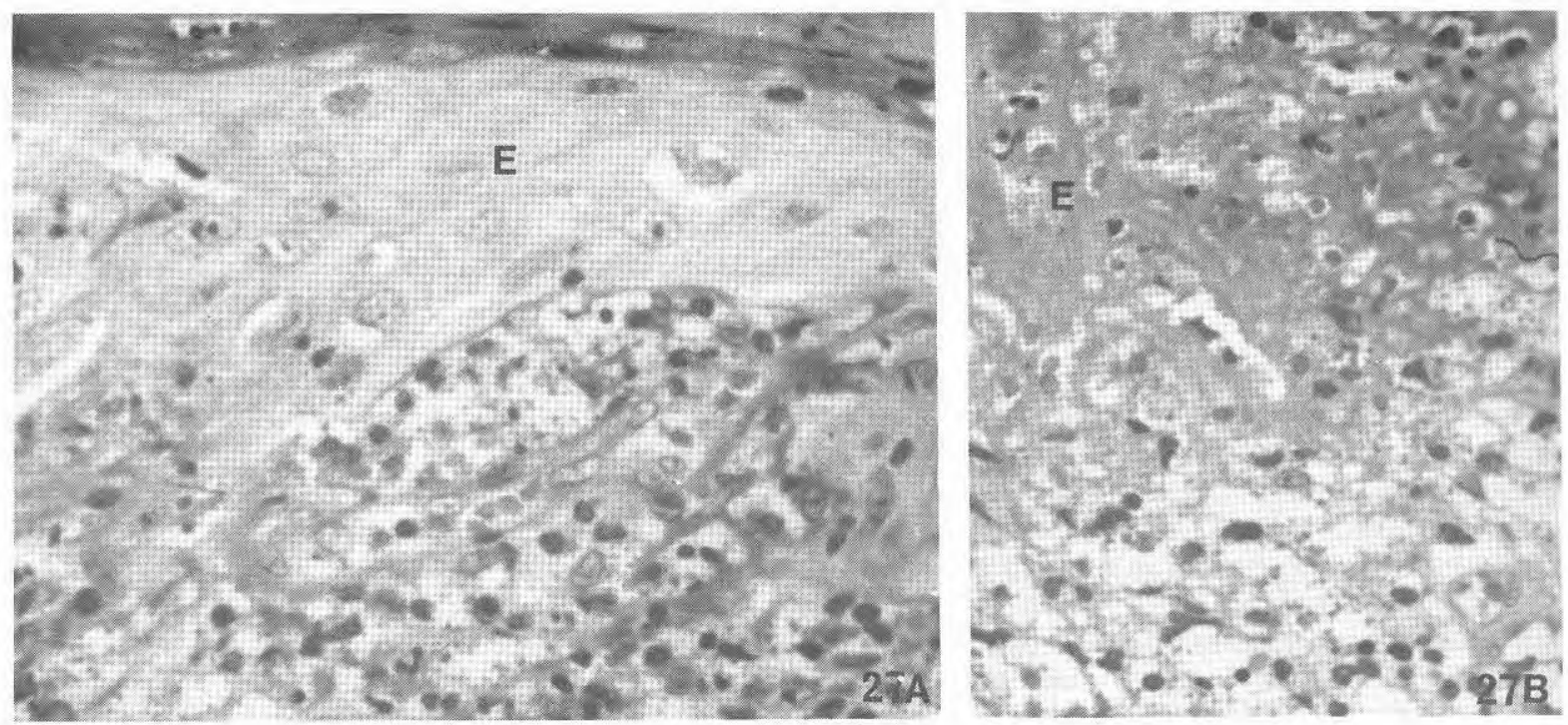

Fig. 27A. Papilas dérmicas con macrófagos vacuolados que contienen numerosos amastigotes que se ven como puntos densos. E: epidermis. B : corresponde al epitelio necrótico $(\mathrm{E})$ del borde de la úlcera, a través del cual se están eliminando macrófagos cargados de parásitos. HE, $4.00 \mathrm{X}$.

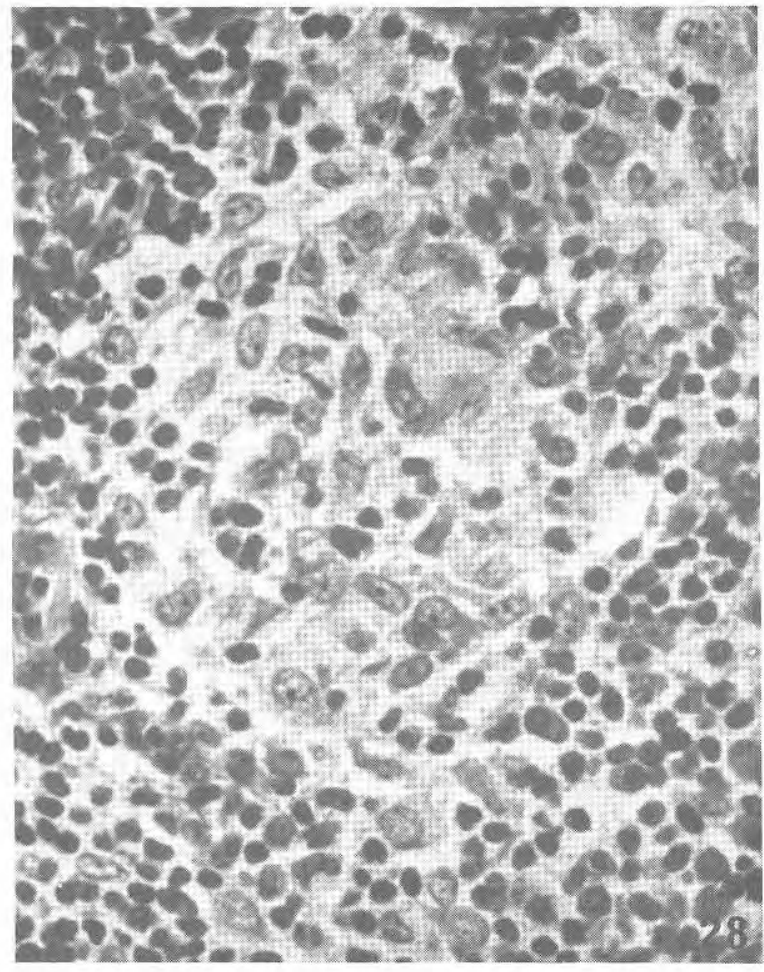

Fig. 28. G ranuloma epiteliode rodeado de linfo y plasmocitos. HE. $400 \mathrm{X}$.

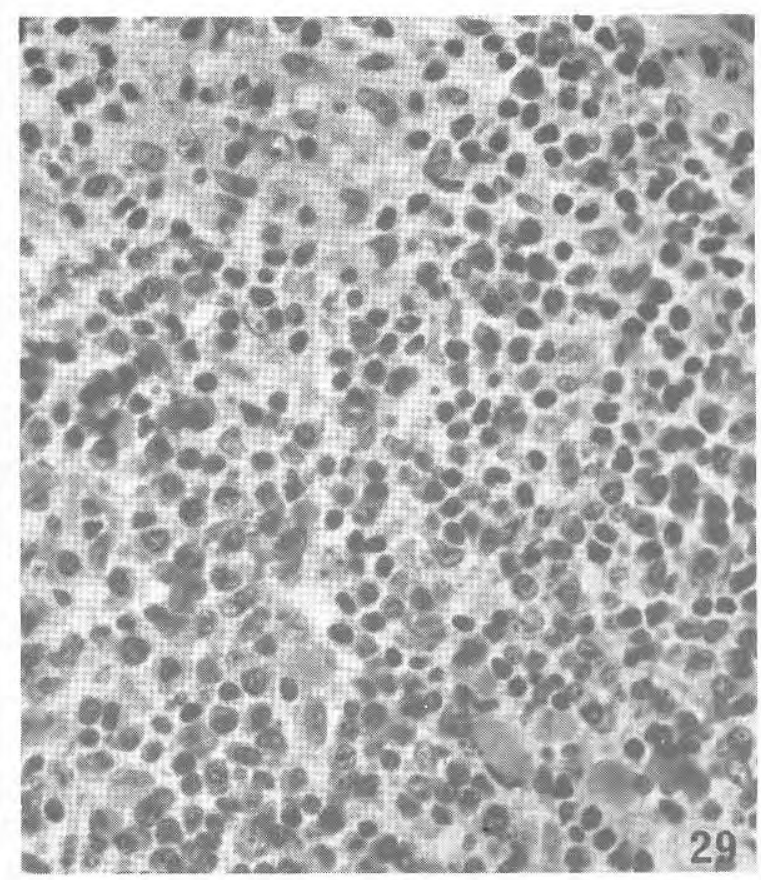

Fig. 29. Infiltrado masivo plasmocitario con algunos cuerpos de Russell (abajo, derecha). Arriba, al centro, un grupo de histiocitos contienen escasas leishmanias. HE. $400 X$. 
gran número de parásitos en los macrófagos de todo el SRE, con ocasionales granulomas en el hígado, el bazo y los ganglios linfáticos. En los aspirados de médula ósea las leishmanias libres pueden predominar sobre las fagocitadas. El parásito puede demostrarse en mononucleares circulantes.

\section{PATOGENIA}

Las leishmanias son parásitos de los macrófagos (Figs. 1-3), aunque a veces puedan parasitar otras células, como los queratinocitos (Figs. 24-25). Los promastigotes inoculados por el mosquito son fagocitados por macrófagos e inician la transformación en amastigotes dentro del fagosoma, en donde sobreviven y se multiplican, resistiendo la acción lisosómica del macrófago (Figs. 1-3), (21-23), tal vez mediante la producción de secreciones, o mediante una cubierta especial de fosfatasa ácida, demostrada en cepas de L. donovani (22-23)

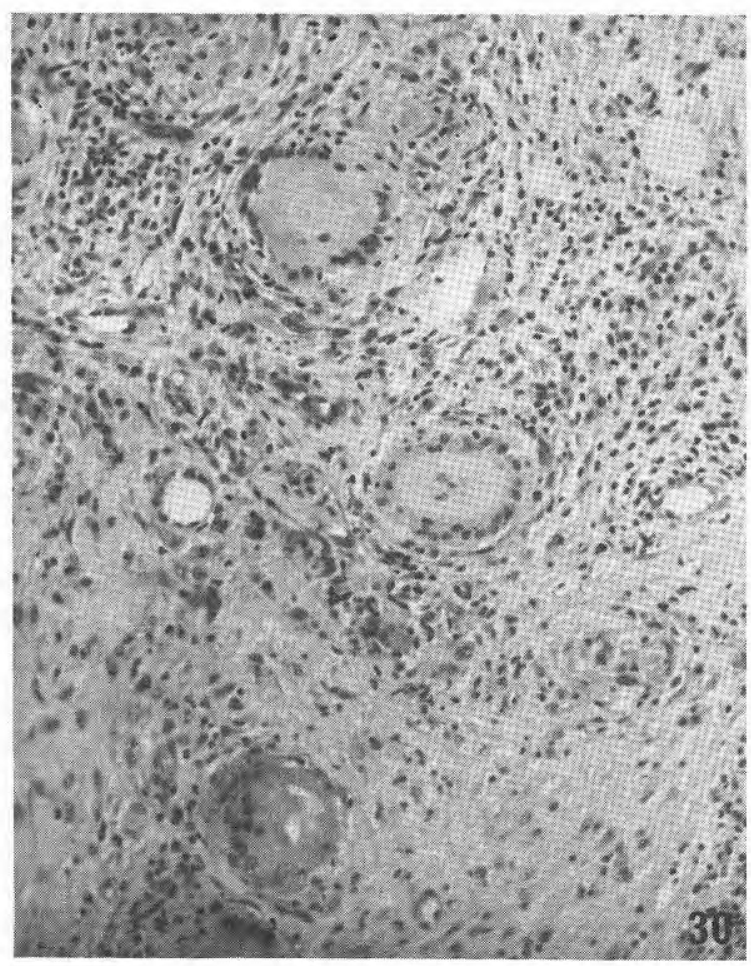

Fig. 30. Granuloma con células gigantes $\mathrm{y}$ fibrosis. $400 \mathrm{X}$.
La respuesta inflamatoria del huésped es notoria, con aflujo de macrófagos y linfocitos. Los plasmocitos, que reflejan la respuesta humoral, son siempre muy abundantes en nuestras biopsias de leishmaniasis (Figs. 28-29). La extensión y persistencia de las lesiones son el resultado de hipersensibilidad del huésped, desproporcionada ante la magnitud del antígeno. Se traduce en la fácil demostración de necrosis fibrinoide, el aumento del número de mastocitos y la vasculitis (24) (Figs. 31-33).

El parásito no tiene efecto tóxico, deletéreo por si mismo. Los macrófagos parasitados pueden eliminarse transepidermicamente (Fig. 27) o se destruyen como resultado de llenarse de parásitos 0 , eventualmente, como mecanismo defensivo, que libera los amastigotes al espacio extracelular. Se originan asi pequeños focos de necrosis con cariorrexis y fondo fibrinoide, en los que se ven amastigotes libres. Con el tiempo, los mecanismos inmunológicos adecuados terminan en la activación del macrófago y éste es entonces capaz de destruír las leishmanias (Figs. 34-37) (23). Posiblemente así ocurre la curación espontánea, que deja inmunidad permanente frente al parásito específico. A veces pueden presentarse recidivas locales y en algunos casos de infección por L. b. braziliensis, la aparición de lesiones mucosas, meses o años más tarde. Los intentos de valorar y clasificar la leishmaniasis de acuerdo con el tipo de infiltrados, en forma similar a lo realizado en la lepra, no ha producido resultados que se puedan generalizar (25).

En las formas viscerales los macrófagos se llenan de parásitos que comprimen el parénquima y originan visceromegalias. Existe una producción masiva de inmunoglobulinas, sin mayor especificidad contra el parásito. La anemia severa puede tener un origen autoinmune (26). La pancitopenia traduce el reemplazo de la médula ósea por macrófagos parasitados. En esta entidad y en la leishmaniasis difusa, ambas formas anérgicas de leishmaniasis, no hay curación espontánea y sólo el tratamiento intenso y en fases no avanzadas de la enfermedad, puede dar resultados satisfactorios. 

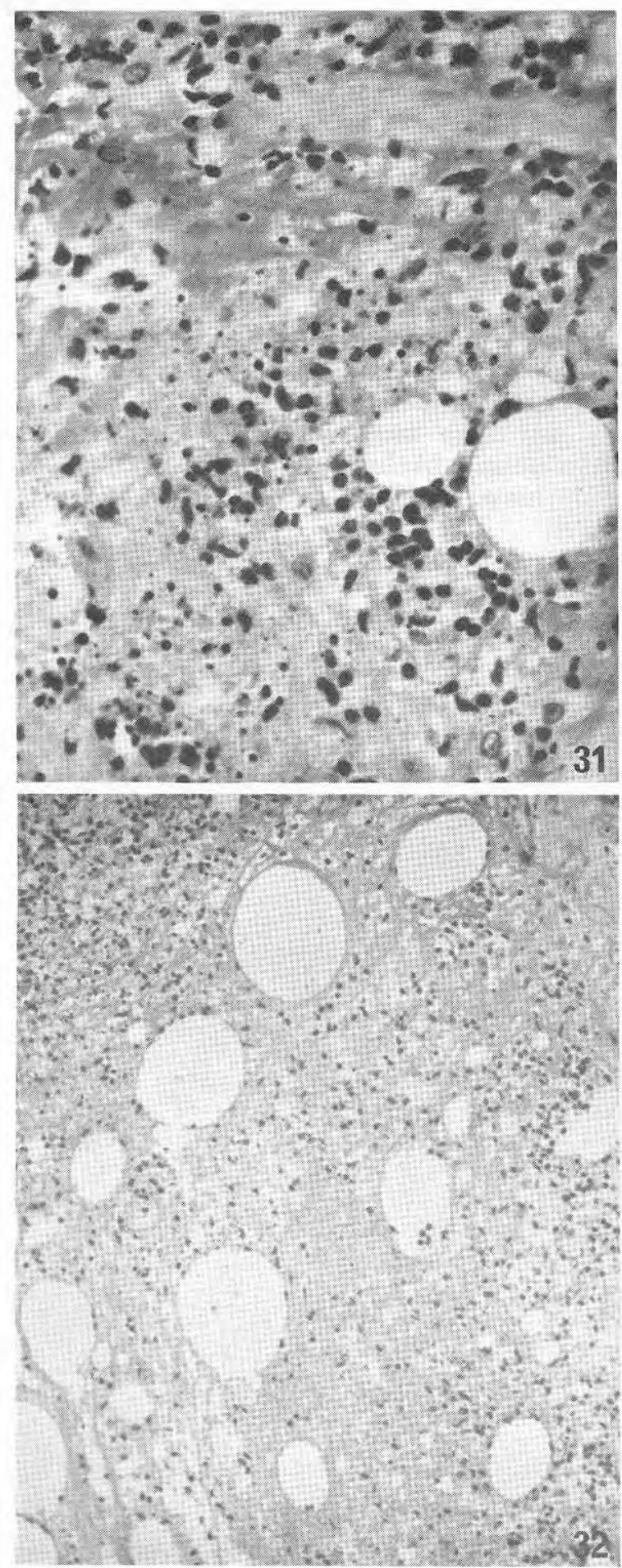

Figs. 31 y 32 . $\mathbf{N}$ ecrosis de la grasa con depósito fibrinoide, leucocitolasia y trombosis venocapilar. HE. 400 y $160 \mathrm{X}$.

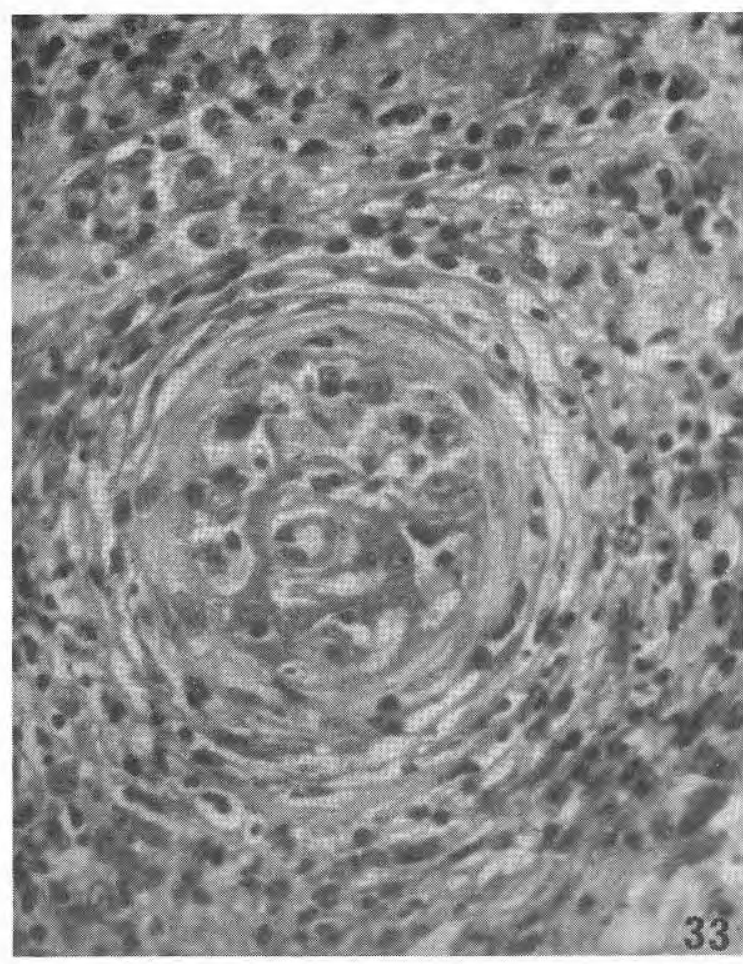

Fig. 33. Trombosis, hialinización y fibrosis en una vena de pequeño calibre. La biopsia de este paciente era muy rica en parásitos. HE. $400 \mathrm{X}$.

\section{DIAGNOSTICO}

El diagnóstico clínico se comprueba por el hallazgo de los parásitos en extendidos de linfa del borde activo de las úlceras, por el aislamiento del germen en cultivo, por la inoculación del material sospechoso en el hocico y almohadillas plantares del hámster o mediante la demostración de los amastigotes en las biopsias. Estas son el procedimiento más usado para diagnóstico, después del frotis directo. En nuestro laboratorio revelan los parásitos en 55\% de los casos. Creemos que aún en la ausencia de amastigotes permiten sugerir la entidad y descartar otras lesiones con las cuales se confunde la leishmaniasis, como la esporotricosis, la cromomicosis, la tuberculosis verrugosa, la paracoccidioidomicosis y algunos tumores. En las lesiones mucosas permiten establecer un diagnóstico diferencial con el escleroma, 
con las micosis sistémicas, las micobacteriosis y con las lesiones vasculíticas y malignas del complejo del granuloma letal de la línea media. Igualmente, ayudan a descartar las úlceras traumáticas y banales que originan perforación del tabique nasal. Cada vez es más extendido el uso de la inmunofluorescencia indirecta, que presenta una buena correlación de sensibilidad y especificidad. Un título igual o mayor de 1:16 se considera positivo (27).

\section{REACCION DE LA LEISHMANINA (MONTENEGRO)}

Consiste en inyectar $0.1 \mathrm{ml}$ intradérmico de promastigotes inactivados con fenol, con concentraciones entre 8 y 12 millones de parásitos por ml. La prueba se lee a las 48 horas.

En las personas que han sufrido infección leishmaniásica previa se presenta una induración local, que se considera positiva cuando es mayor de $5 \mathrm{~mm}$ (28) (Fig. 22). El eritema local debe valorarse cuidadosamente pues el diluyente puede originarlo inespecíficamente. La prueba, como toda reacción de hipersensibilidad retardada, mide exposición previa al antígeno y no necesariamente indica enfermedad, por lo cual no debe tomarse como una prueba diagnóstica absoluta. Su positividad tiene desde luego un gran valor para apoyar un

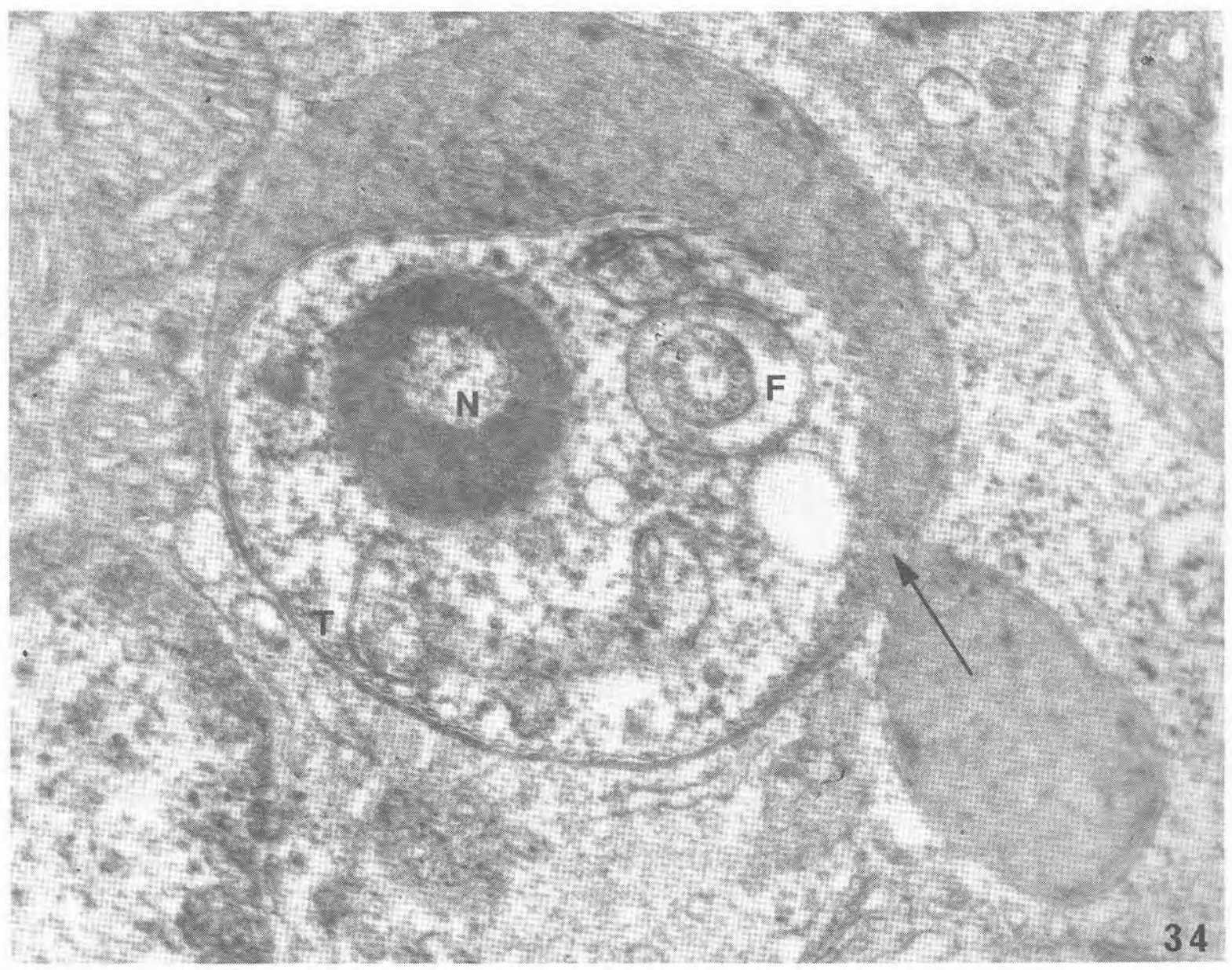

Fig. 34. Un amastigote relativamente bien preservado se ve en un fagolisosoma, al cual parece drenarse nuevo contenido lisosómico (flechas). Leishmaniasis experimental en el hámster. M acrófago del bazo. F : flagelo; $\mathbf{N}$ : núcleo; $T$ : microtúbulos. $40.000 \mathrm{X}$. 


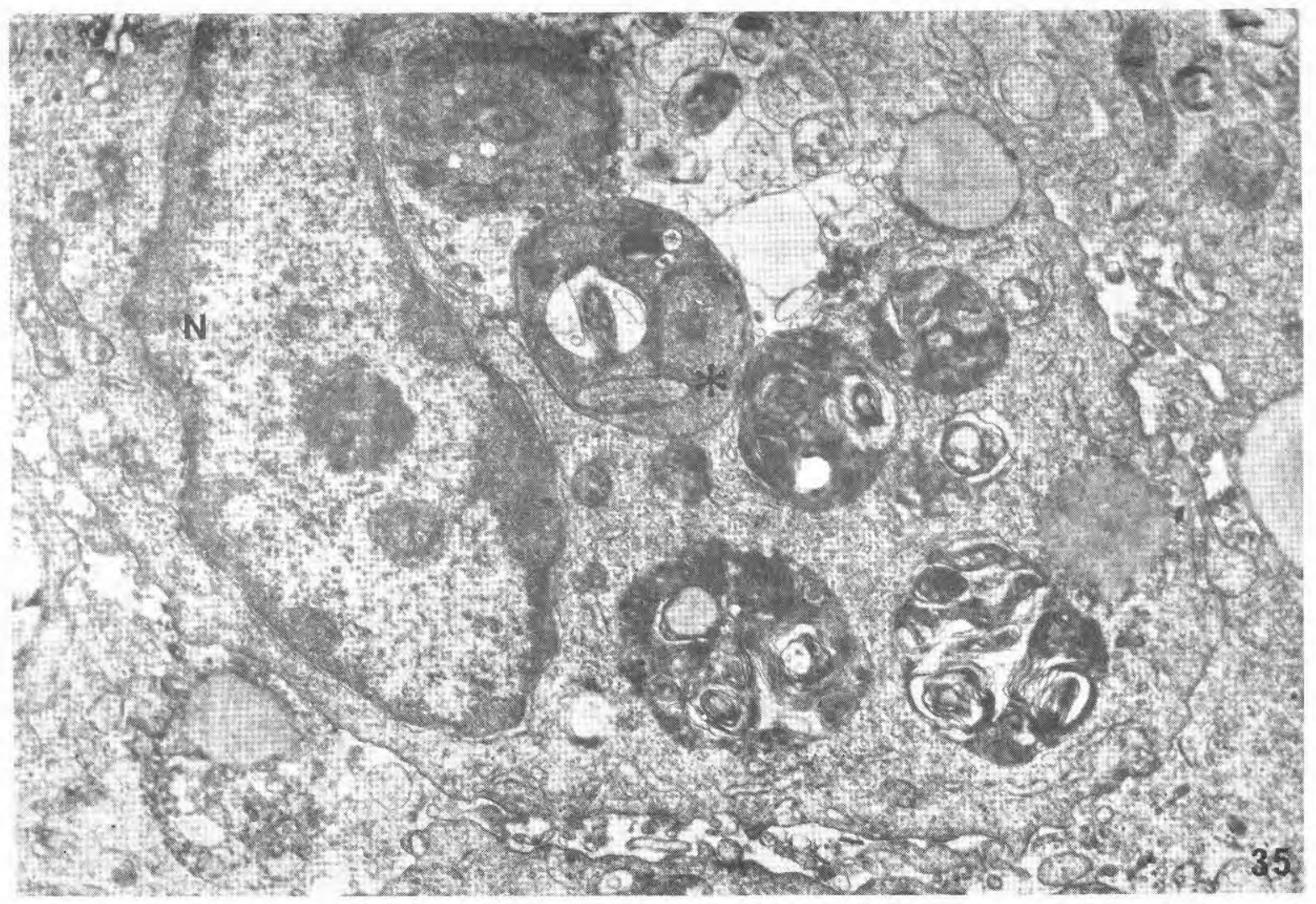

Fig. 35. La mayoría de los amastigotes en este macrófago se han convertido en figuras osmiofílicas, lamelares. El parásito indicado con el asterisco todavía conserva su morfología reconocible. Estos parásitos no son reconocidos como tales al microscopio de luz, donde se ven como gránulos eosinófilos. N : núcleo del macrófago.Leishmaniasis cutánea. $16.000 \mathrm{X}$.

diagnóstico clínico o histológico, cuando no se ven los parásitos, especialmente en las lesiones mucosas. Ante un cuadro clínico sugestivo de leishmaniasis mucosa, con presencia de una "cicatriz cutánea leishmaniásica" (Fig. 21) y una reacción de Montenegro positiva, las posibilidades de leishmaniasis mucosa son muy grandes como para justificar la iniciación de un tratamiento de prueba.

\section{TRATAMIENTO}

Los antimoniales pentavalentes son la droga de elección. El Glucantime (R) (antimoniato de N-metilglucamina) se presenta en ampollas de $5 \mathrm{ml}$. que contienen $1.500 \mathrm{mg}$ de $\mathrm{N}$-metilglucamina, principio activo, que se da a la dosis de $50-100 \mathrm{mg} / \mathrm{kg}$. Para un adulto de $60 \mathrm{~kg}$ se suministran dos ampollas diarias, de una sola vez, por vía intramuscular y durante 20 días continuos; otra modalidad es la de cursos de 10 días, con descansos de 10 días entre los tratamientos. En los niños se recomiendan 2-3 ml de la ampolla por cada 10 kilos de peso. Los antimoniales pentavalentes se eliminan rápidamente por la orina y no tienen efecto acumulativo (29). Pueden producir náuseas, diarrea, hipersecreción bronquial, dolores articulares, retención nitrogenada y bloqueos cardíacos. Está indicada una determinación de creatinina, transaminasas y cuadro hemático para valorar el estado del paciente previo al tratamiento. La droga está contraindicada cuando hay enferme- 
dades renales, hepatitis, trastornos cardíacos serios y en el embarazo.

La Anfotericina B puede usarse en las lesiones mucosas graves y crónicas rebeldes a los tratamientos usuales (30). Otras drogas como la Rifampicina, el Allopurinol, el Nifurtimox (LampitR), el Metronidazol, tienen eficacia variable y discutida, probablemente con poca utilidad para las formas existentes en nuestro medio (31-34).

El calor local tiene efecto definitivamente benéfico. Puede ser de gran valor como coadyuvante en las lesiones cutáneas rebeldes y en las del pabellón auricular. Debe ser de $41^{\circ} \mathrm{C}$ y aplicado en varias sesiones diarias, con cuidadoso control de la temperatura. La crioterapia con bióxido de carbono (35) ha dado también resultados buenos pero se debe recordar que estos dos tratamientos no previenen la aparición tardía de lesiones mucosas.

En un caso de leishmaniasis lupoide y uno de la forma facial difusa, resistentes a otros tratamientos, la aplicación semanal intralesional de $0.1-0.2 \mathrm{ml}$ de clorhidrato de emetina produjo resultado excelente en pocos meses (36).

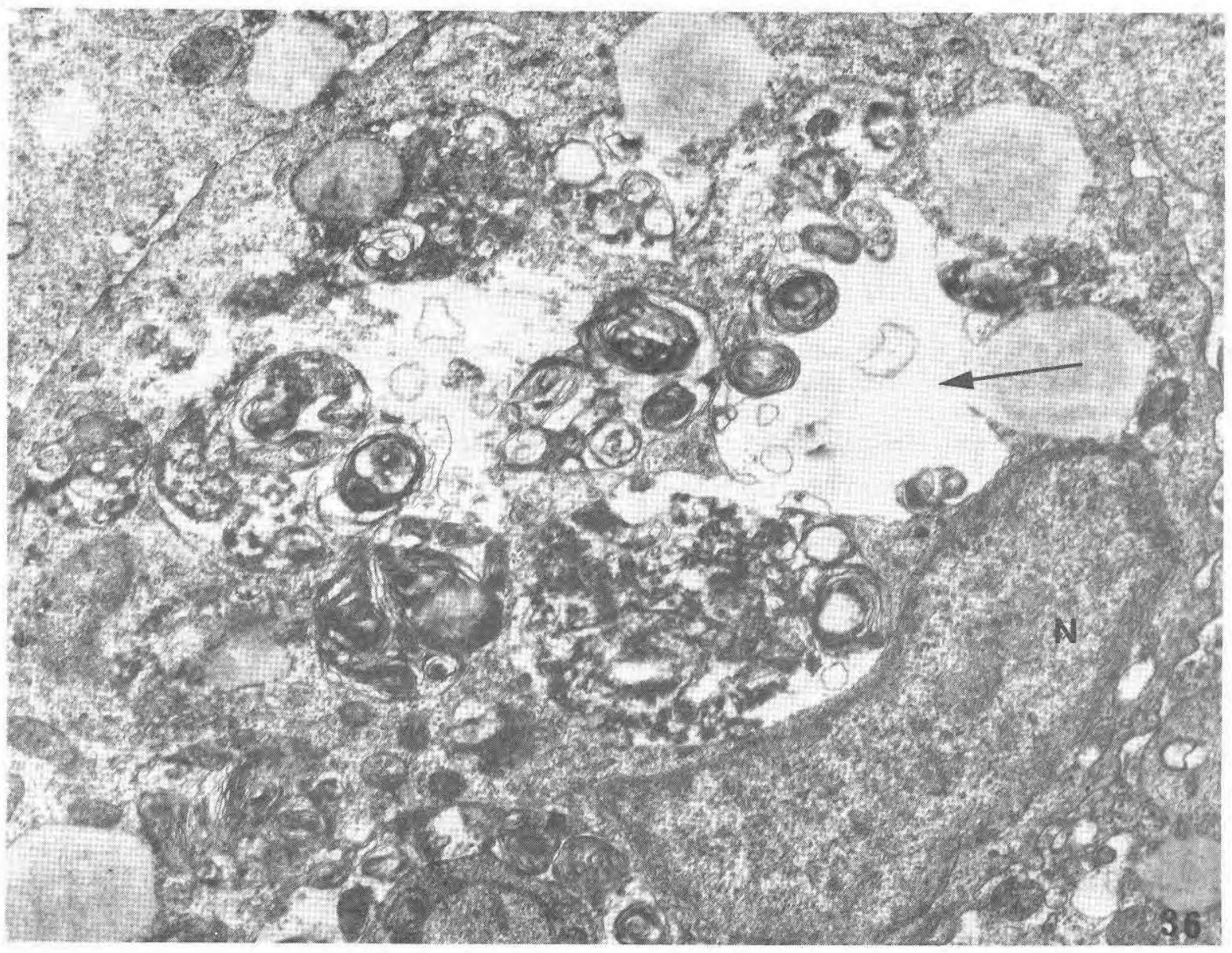

Fig. 36. En este macrófago la digestión y fragmentación de los parásitos está más avanzada. N : núcleo del macrófago. La flecha sugiere que un lisosoma drena su contenido al fagolisosoma. $12.500 \mathrm{X}$. Leishmaniasis cutánea. 
En Nicaragua, el Ketoconazole a razón de $400 \mathrm{mg} /$ día, curó 6 pacientes con formas cutáneas o mucosas de leishmaniasis, en períodos menores de 3 meses (37).

En la leishmaniasis visceral, el uso de fármacos incorporados en liposomas que son fagocitados por los macrófagos del SRE, seguramente permitirá en el futuro la realización de tratamientos más rápidos y efectivos, o el uso de drogas que aunque menos activas por otras vías, aumentan en los liposomas su potencia varios miles de veces (38).

\section{PREVENCION Y CONTROL}

La leishmaniasis cutánea americana es una zoonosis rural o selvática, con vectores y reservorios diferentes (4) que se transmite al hombre cuando entra en contacto con estos nichos ecológicos. La enfermedad humana depende de la transmisión por el vector, que en general tiene hábitos vesperales o nocturnos, pero también puede picar cuando se le molesta en condiciones diurnas. Los insecticidas podrían disminuír las condiciones de transmisión rurales, domiciliarias o peridomiciliarias, en las que el insecto vector invade la vivienda y luego se posa en las paredes.

En la leishmaniasis visceral americana deben sacrificarse los perros, reconocidos claramente como reservorios (7). Como el vector es peridomiciliario, el rociado con insecticida de las zonas afectadas, que en general son pequeños focos, podría ser

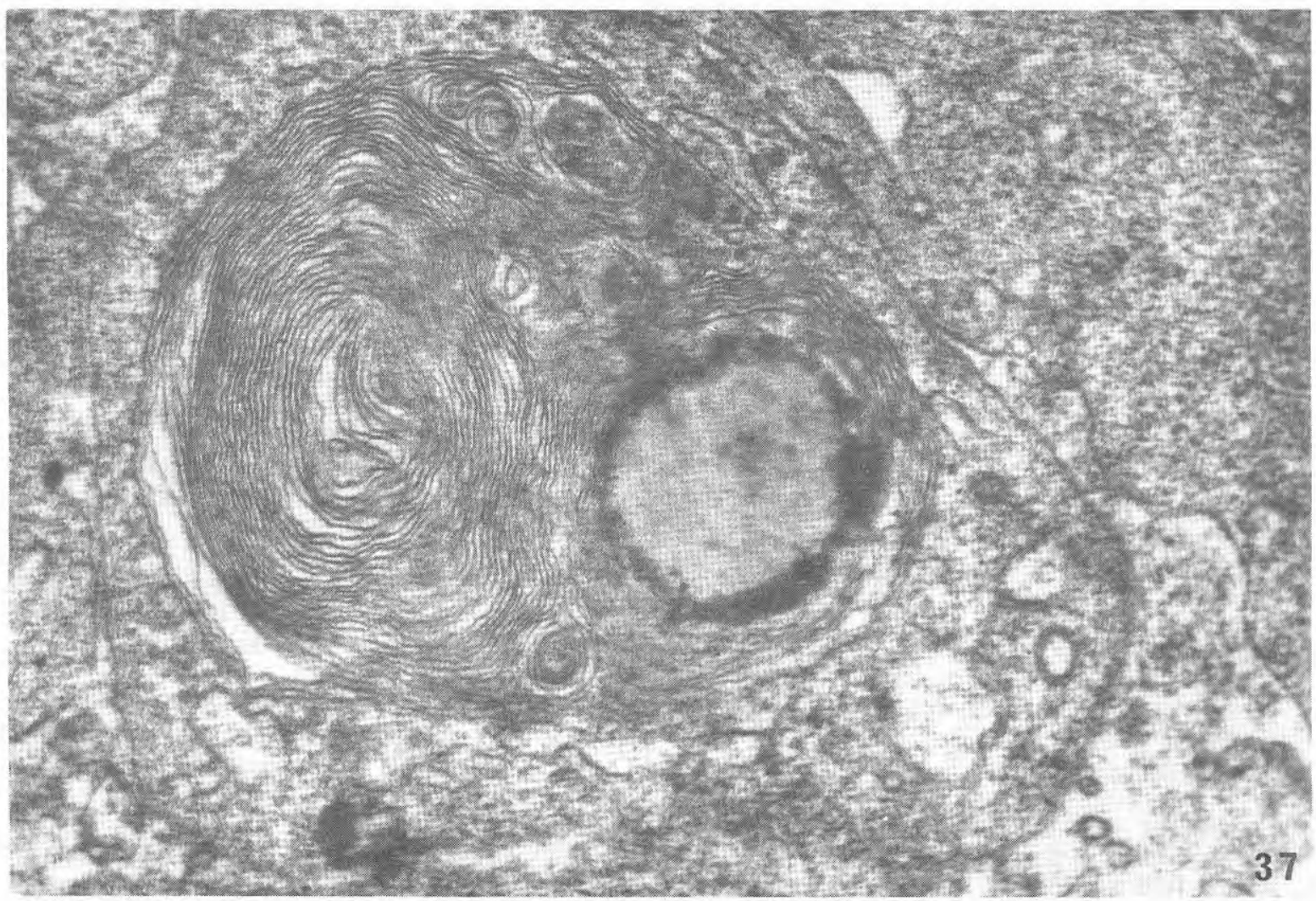

Fig. 37. Transformación lamelar total de un amastigote, con apariencia de lamelas de fosfolípidos. La morfología global y el análisis de varias fotografías permite esta conclusión, pues la imagen es la de un "cadáver de leishmania". Leishmaniasis cutánea. $49.000 \mathrm{X}$. 
beneficiosa. De hecho, es posible que las campañas de rociado para malaria mantuvieron la leishmaniasis visceral en un umbral mínimo y la redujeron al ciclo selvático, con el zorro como reservorio, pero una vez que los rociados disminuyeron se reactivó el ciclo peridomiciliario, con el perro como reservorio y se desencadenaron los actuales brotes epidémicos (7).

El desarrollo de una vacuna y de la prevención de las lesiones mucosas es un objetivo deseable que resultará de un mejor conocimiento de la antigenidad del parásito en el cultivo y en el vector, de la respuesta del huésped y de la relación leishmaniamacrófago, entre otras circunstancias.

\section{AGRADECIMIENTOS}

Al Grupo de Parasitología del INS por suministrarnos cultivos de leishmanias y material experimental en el hámster. Al Dr. J. G. Chalela, por las figuras $9,12,13,15 \mathrm{y}$ 17. Al Dr. José Moreno por la Figura 21. Al Dr. Rómulo Villamizar por la figura $19 \mathrm{y} \mathrm{al}$ Centro Dermatológico "Federico Lleras" por la figura 18.

\section{BIBLIOGRAFIA}

1. Morales A., y cols. Aislamiento de tres cepas de Leishmania a partir de Lutzomyia trapidoi en Colombia. Biomédica 1.981, 1: 198-207.

2. Lainson, R. The American Leishmaniasis: some observations on their ecology and epidemiology. Trans. Roy. Soc. Trop. Med. Hyg. 1983, 77 (5): 569-596.

3. Shaw, J.J. Taxonomy of the Genus Leishmania. Traditionalist's View and modern concepts. In: Biochemical Characterization of Leishmania; Edited by Chance, M.L. and Walton, B.C. PAHO 1980, Washington.

4. Lainson, R., and Shaw, J.J. Epidemiology and Ecology of Leishmaniasis in Latin-America. Nature 1978, 273: 595-600.

5. Herrer, A., and Christensen, H.A. Leishmania braziliensis in the Panamian Two - toed Sloth, Choloepues hoffmani. Amer. J. Trop. Med. Hyg. 1980, 29: 1196-1200.
6. Herrer, A., et al. Reservoir of Cutaneous Leishmaniasis Among Panamian Forest Mammals. Am. J. Trop. Med. Hyg 1973, 22: 585-591.

7. Corredor, A., y Cols. Leishmaniasis Visceral Americana. Boletín Epidemiológico, Bogotá Colombia, Ministerio de Salud, 1982.

8. Marinkelle, C.J. y Rodríguez, E. Progresos en Leishmaniasis. Tribuna Médica 1981, 11: 1-6.

9. Petersen, E.A., and cols. Specific Inhibition of Lymphocyte Proliferation responses by adherent suppresor cells in diffuse cuteneous Lehishmaniasis. N. Engl. J. Med. 1982, 306: 387-392.

10. Rodríguez, J. del C. Contribución al estudio de la leishmaniasis tegumentaria en Colombia (Bubón de Vélez, marranas, Espundia). 1929. Tesis Facultad de Medicina. Universidad Nacional. Bogotá, pp. 172.

11. Werner, J.K., and Barreto, P. Leishmaniasis in Colombia, A Review. Am. J. Trop. Med. Hyg. 1981, 30 (4) : 751- 761.

12. Corredor, A., y Ronderos, M. Curso sobre Leishmaniasis y Trupanosomiasis Americanas. Bogotá, 21-26 noviembre, 1982.

13. Restrepo, M., y col. Leishmaniasis tegumentaria americana. Tribuna Médica - Bogotá, 1975, 52: (1): A 13-A16.

14. Abdalla, R.E., et al. Sudan Mucosal Leishmaniasis. Trans. Roy Soc. Trop. Med, Hyg 1975, 443-449.

15. Villela, F., y col. Presenca de Leishmania brasiliensis na mucosa nasal sem lesao aparente, em casos recentes de Leishmaniasis. Hospitàl (Río Janeiro) 1939, 16: 953-960.

16. Walton, B.C., et al. Onset of Espundia After Many Years of Occult Infection With Leishmania braziliensis. Am. J. Trop. Med. Hyg. 1973, 22: 696-698.

17. Sampaio, R.N.R. y col. Leishmaniose Tegumentar Americana. Casuística do Hospital Escola de Un B. An. Bras. Dermatol 1980, 55: 69-76.

18. Rocha, R., et al. Apparent Glucantyme failure in five patients with mucocutaneous leishmaniasis. J. Trop. Med. Hyg. 1980, 83: 131-139.

19. Gast, A. Primer caso de Leishmaniasis Visceral en Colombia. Anales de la Soc: de Biología de Bogotá 1944, 1: 124. 
20. Campos, M. y cols. Leishmaniasis Visceral en el Huila. Informe Preliminar de 25 casos. Acta Médica Colombiana 1982, 7: 161-170.

21. Bloom, B.R. Games parasites play: How parasites evade immune surveillance. Nature 1979, 279: 21-26.

22. Chang, K.P. and Dwyer, D.M. Multiplication of a human parasite (Leishmania donovani) in Phagolisosomes of Hamster Macrophages in vitro. Science 1976, 193: 678-680.

23. Sandbank, M., et al. The role of Lysosomes in the healing process of cutaneous leishmaniasis. Int. J. Dermatol 1979, 18 (1): 50-54.

24. Lisboa Bittencourt, A., y Andrade, A.Z Aspectos Inmunopatológicos en la Leishmaniasis mucocutánea. Hospital 1967, 71: 89.

25. Ridley S.D., et al. A histological classification of mucocutaneous Leishmaniasis in Brazil and its Clinical Evaluation. Trans. Roy. Soc. Trop. Med. Hyg 1980, 74: 508-521.

26. Sirol, J., et al. Physiopathologie de L'Anémie das le Kala-Azar. Med. Trop. 1978, 38: 399-400.

27. Restrepo, M, y Gómez, M.E. La reacción de inmunofluorescencia indirecta en el diagnóstico de la leishmaniasis tegumentaria americana. Biomédica 1983, 3 (1-2).

28. Restrepo, M. La reacción de Montenegro en la Epidemiología de la Leishmaniasis Sudamericana. Bol of Sanit. Panam. 1980, 89: 130-138.
29. Rees, PH., et al. Renal Clearence of Pentavalent Antimony (Sodium-Stibogluconate). Lancet 1980, 2: 226-229.

30. Londoño, F., y Gutiérrez, G. Tratamiento Experimental de la Leishmaniasis Cutáneomucosa Americana con Anfotericina B. Trib. Méd. 1964, 3: 148.

31. Marsden, P.D., et al. Nifurtimox in the treatment of South American Leishmaniasis. Trans. R. Soc. Trop. Med. Hyg 1979, 73: 391-394.

32. Walton, B.C., et al. American Cutaneous Leishmaniasis. Inefficacy of Metronidazole in Treatment. JAMA 1974, 228: 1256-1258.

33. Restrepo, M., Velázquez, J.P., et al. Tratamiento de pacientes con Leishmaniasis. Empleo del compuesto nitrofuránico "Bay 2502". Trib. Med. 1976, LIV : 36.

34. Restrepo, M. Leishmaniasis. Acta Médica Colombiana $1980,5: 161-162$.

35. Bassiouny, A., et al. Criosurgery in Cutaneous Leishmaniasis. Br. J. Dermatol 1982, 107 (4) : 467.

36. Tohen, H., and Wahaba, A. Treatment of Leishmaniasis recidivans with intralesional injections of Emetine Hydrochloride: A case report. Acta Dermatovener 1979, 59: 549-553.

37. Gómez, U.F., and Zaias, N Oral Ketoconazole in the treatment of leishmaniasis. Int. J. Dermatol 1982, 21 (7): 414-416.

38. Alving, C.R., et al. Liposomes in leishmaniasis: therapeutic effects of antimonial drugs, 8aminoquinolines and tetracycline. Life Sc., 1980, 26: 2231-2238.

\section{CORRIGENDUM}

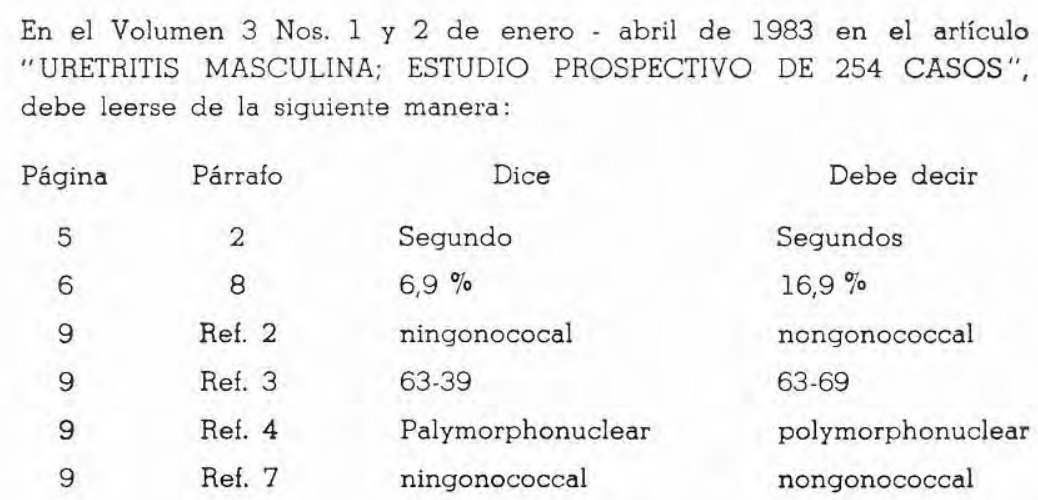




\section{INSTRUCCIONES PARA LOS AUTORES}

1. Biomédica la revista del Instituto Nacional de Salud recibirá para publicación únicamente artículos originales e inéditos.

2. La revista aceptará artículos que contribuyan a ampliar los conocimientos sobre biomedicina realizadas, tanto en el Instituto Nacional de Salud como en cualquier otro centro investigativo.

Dichos artículos deberán llenar los siguientes requisitos:

a) Ser enviados al editor de la revista, Apartados 80334 y 80080, Zona 6, Bogotá, D.E., Colombia S.A.

b) Ser escritos a máquina, a doble espacio, en original y una copia, dejando márgenes de 4 $\mathrm{cms}$. a la izquierda y $2 \mathrm{cms}$. a la derecha. El original en papel blanco, grueso, tamaño carta.

c) Ser escritos en español con resúmenes en español e inglés.

d) Tener un título conciso. Podrán tener, si fuere necesario, un subtítulo explicativo.

e) Llevar los nombres del autor o los autores inmediatamente después, indicando con asteriscos, en el pié de página, su título académico y la institución en la cual se realizó el trabajo.

f) Incluir en el texto del trabajo: Introducción, Materiales y Métodos, Resultados, Discusión, Conclusiones y Referencias Bibliográficas.

g) Las citas bibliográficas se harán en el texto en forma consecutiva, utilizando números arábigos y deberán aparecer, en el mismo orden numérico de citación. La referencia se presenta así: apellido del autor, seguido de las iniciales de su nombre, título del artículo, nombre abreviado de la revista, año de publicación, volumen, número y pagina .

Ejemplo: Barrow CH. Criptococcosis in animals. J.A. M.A. 1955, 127: 125.

Para la citación de libros se seguirá un orden similar, así: Pearse A., Texbook of Biochemistry; Saunders Edt., 1979; pp 49-50.

h) Los cuadros, gráficas y figuras deben numerarse en forma consecutiva con números arábigos y ser presentados en papel fotográfico brillante, en blanco y negro, manteniendo individualmente una proporción de $2 \times 3$. Dicho material debe ser de calidad y presentación impecables. En hoja aparte se incluirá la leyenda respectiva.

3. La revista también aceptará para publicación: actualizaciones, memorando, revisiones, comunicaciones breves, cartas al editor, revisión de resúmenes e informes técnicos.

4. Todo material propuesto para publicación será revisado por el Comité Editorial. El Editor informará a los autores, tanto sobre la recepción de los trabajos, como sobre la decisión final que se tome.

5. La revista se reservará el derecho de aceptar o rechazar los artículos y podrá hacer sugerencias que tiendan a mejorar su presentación. Para un mejor cumplimiento de esta función el Comité Editorial podrá consultar a especialistas en la materia.

6. Los originales de los articulos publicados permanecerán en los archivos de la revista; aquellos no aceptados para publicación, serán devueltos a sus autores.

7. El autor principal recibirá libre de costo 5 ejemplares de la revista. Los reimpresos deberán ser sufragados por el autor.

NOTA: Las personas interesadas en adquirir la revista podrán hacerlo en la biblioteca del Instituto Nacional de Salud, a un costo de ciento veinticinco pesos m/cte. $(\$ 125.00)$ cada ejemplar, o tomando una suscripción anual. 